Article

\title{
Cost-Effectiveness of Seven Approaches to Map Vegetation Communities - A Case Study from Northern Australia's Tropical Savannas
}

\author{
Donna Lewis ${ }^{1,2, *}$, Stuart Phinn ${ }^{2}$ and Lara Arroyo ${ }^{3}$
}

1 Northern Territory Herbarium, Department of Land Resource Management, Northern Territory Government, Ground Floor, Herbarium Building, The Boulevard, Palmerston, NT 0831, Australia

2 Biophysical Remote Sensing Group, Centre for Spatial Environmental Research, School of Geography, Planning and Environmental Management, The University of Queensland, St Lucia, Brisbane, QLD 4072, Australia; E-Mail: s.phinn@uq.edu.au

3 Centre for Human and Social Sciences, Spanish Council for Scientific Research, Albasanz 26-28, 28037 Madrid, Spain; E-Mail: lara.arroyo@cchs.csic.es

* Author to whom correspondence should be addressed; E-Mail: donna.lewis@nt.gov.au; Tel.: +61-8-8999-4470; Fax: +61-8-8999-4527.

Received: 27 November 2012; in revised form: 4 January 2013 / Accepted: 4 January 2013 / Published: 18 January 2013

Abstract: Vegetation communities are traditionally mapped from aerial photography interpretation. Other semi-automated methods include pixel- and object-based image analysis. While these methods have been used for decades, there is a lack of comparative research. We evaluated the cost-effectiveness of seven approaches to map vegetation communities in a northern Australia's tropical savanna environment. The seven approaches included: (1). aerial photography interpretation, (2). pixel-based image-only classification (Maximum Likelihood Classifier), (3). pixel-based integrated classification (Maximum Likelihood Classifier), (4). object-based image-only classification (nearest neighbor classifier), (5). object-based integrated classification (nearest neighbor classifier), (6). object-based image-only classification (step-wise ruleset), and (7). object-based integrated classification (step-wise ruleset). Approach 1 was applied to 1:50,000 aerial photography and approaches 2-7 were applied to SPOT5 and Landsat5 TM multispectral data. The integrated approaches $(3,5$ and 7 ) included ancillary data (a digital elevation model, slope model, normalized difference vegetation index and hydrology information). The cost-effectiveness was assessed taking into consideration the accuracy and costs associated with each classification approach and image dataset. Accuracy was assessed in 
terms of overall accuracy and the costs were evaluated using four main components: field data acquisition and preparation, image data acquisition and preparation, image classification and accuracy assessment. Overall accuracy ranged from $28 \%$, for the image-only pixel-based approach, to $67 \%$ for the aerial photography interpretation, while total costs ranged from AU $\$ 338,000$ to AU\$388,180 (Australian dollars), for the pixel-based image-only classification and aerial photography interpretation respectively. The most labor-intensive component was field data acquisition and preparation, followed by image data acquisition and preparation, classification and accuracy assessment.

Keywords: cost-effectiveness; accuracy assessment; ancillary data; remote sensing; Landsat5 TM; SPOT5; aerial photography

\section{Introduction}

There is an increased requirement for reliable and up-to-date vegetation community information across the globe [1,2]. Due to an increasing population, natural resources are compromised as more land is required to accommodate agricultural, residential, industrial and commercial activities. This results in extensive land clearing of native, often remnant vegetation [1-3]. Without reliable vegetation spatial information, sound decision making for natural resource management and biodiversity conservation is jeopardized. Furthermore, the vegetation datasets that are available are too coarse to make decisions at a local or property management scale. Vegetation community mapping is being practiced in most parts of the world. The numerous methods used continue to evolve and adapt to the diversity of vegetation types found.

There are a number of techniques commonly used to map vegetation communities. The traditional method is aerial photography interpretation (API) and intensive field sampling. Two semi-automated methods include pixel-based image analysis (PBIA) and geographic object-based image analysis (GEOBIA). API is a method that requires manual stereoscopic interpretation of aerial photograph pairs. The use of aerial photography was anticipated to decrease as technological advances improved in the capabilities of new airborne and satellite sensors, however, it continues to be a universal and acceptable method for numerous mapping applications [4,5]. API is documented as an expensive, time consuming and inefficient process even though aerial photography is available digitally [6-10].

Semi-automated techniques are becoming increasingly available as a result of developing image processing software. These software packages now offer a realm of pixel and object-based functions for discriminating vegetation communities from commercially available image datasets. Pixel-based classification assigns individual pixels to a class according to their statistical characteristics. Object-based classification first groups or segments neighboring pixels with similar characteristics and then assigns each segment to a class [11]. While these methods have been used for decades, there is a lack of research that compares the accuracy and cost-effectiveness of the common approaches applied to various image datasets and spatial scales. Although GEOBIA emerged as early as the 1970s, GEOBIA was not used extensively within the field of remote sensing until recently [12-14]. Some 
comparative studies have highlighted strengths and weaknesses of each approach and further recommend a combination of the two can be beneficial $[11,15]$.

Existing studies have compared aspects of land cover and vegetation community maps, such as spatial scale [2], spatial versus spectral resolution [16-18], the influence of ancillary data on classification results [6-8,19-24], and the accuracy of these types of maps [25]. However, few studies have presented an analysis of cost or even generic discussion of cost-effectiveness of remote sensing applications. Cost-effectiveness herein refers to the accuracy of thematic mapping products and the costs and time associated to generate the end mapping product. The evaluation of cost appears to be limited by the large number of variables to consider, including survey purpose, hardware availability, size of study area, technical expertise of staff, cost of data acquisition, intended accuracy, and so on. In tropical savanna environments, there are few publications on the cost of evaluations for vegetation community mapping applications. The majority of cost evaluations for vegetation community mapping programs seem to reside internally as unpublished documents [26]. Also, mapping programs in some Australian jurisdictions have assessed the costs in artificial situations but are not related so much to actual operational costs that happen in practice [27].

Research that does exist on cost-effectiveness of remote sensing techniques is focused more on tropical coastal habitat mapping [28-30]. A toolkit developed by United Nations Educational, Scientific and Cultural Organization (UNESCO) is also available for assessing the cost-effectiveness of remote sensing for coastal management [31]. Several coastal habitat mapping projects acknowledge it is difficult to place a monetary value on remotely sensed information despite its great utility in coastal systems [29]. The frameworks that have been developed for coastal environments have generally identified key cost categories, including set-up costs, field survey costs, image acquisition costs, and costs associated with field data analysis and image processing. A framework has also been developed, initially for coastal environments, to enable spatial data collection needs to be linked to a suitable form of remotely sensed data [30]; however, this framework does not incorporate cost-effectiveness.

Accuracy assessment is another essential constituent of cost-effectiveness and is regarded as a fundamental component of thematic mapping from remotely sensed data. Many problems are encountered when assessing the accuracy of image classification as there is no single, universal and acceptable measure [32-34]. The most widely used approach is the derivation of confusion or error matrices $[8,33,35]$, and is applied in this study. After generating an error matrix, accuracy assessment metrics, such as overall accuracy, producer and user accuracies, can be derived [8]. It has also been customary to report Kappa coefficient which became a standard component of almost every accuracy assessment, however, recent papers by Pontius and Millones [36] and Foody [37] report the redundancy of Kappa as a result of misleading information for practical decision making, and we reflect this premise accordingly. Accuracy assessment of vegetation community maps, and similarly land cover maps generated from remotely sensed data, provides important data quality information $[8,32,33,35,38]$. Given the complexity of remotely sensed classifications, there is a requirement to assess the reliability. Traditionally, API has been accepted to be correct without any form of accuracy assessment [35]. However, for semi-automated approaches such as PBIA and GEOBIA, accuracy assessment is common practice. Thus, there is a glaring inconsistency in the application of accuracy assessment applied to various mapping techniques which presents a need for 
comparative research. We address this gap in knowledge herein by comparing the accuracy of API, PBIA and GEOBIA generated vegetation community thematic maps.

Existing cost-effective frameworks highlight the urgency of cost-effective evaluations if managers are to make appropriate choices when faced with the growing plethora of remote sensing technologies [28], especially where the potential benefits and costs are very large. Project managers prefer the least expensive remote sensing technique that will achieve a given task with an acceptable degree of accuracy [39]. This study assesses the cost-effectiveness of seven vegetation community mapping approaches applied to 1:50,000 aerial photography, SPOT5 and Landsat5 TM multi-spectral data. Some of the approaches integrate ancillary data in the classification processes, including a digital elevation model (DEM), DEM-derived slope model, normalized difference vegetation index (NDVI) and hydrology information. Field data were used for each approach, 50\% for the classification processes and the remaining 50\% for the accuracy assessment. Two spatial scale maps $(1: 25,000$ and 1:100,000) were generated for each approach and image dataset. The cost-effectiveness comprised four main cost components and was assessed in terms of overall accuracy and the costs associated with each approach and image dataset. We provide the first cost-effectiveness study for a tropical savanna environment to map the floristic and structural components of vegetation communities at a property management scale $(1: 25,000)$ and regional scale $(1: 100,000)$, whilst also comparing numerous techniques and image datasets. Three major comparisons are included in this study in terms of cost-effectiveness: seven mapping approaches, three image datasets, and two spatial resolution outputs.

\section{Data and Methods}

\subsection{Study Area}

The study area is located on Bullo River Station in the Victoria River District in north western Northern Territory, Australia (Figure 1). The study area covers $530 \mathrm{~km}^{2}$ and is situated in the Bullo River catchment, representing three broad landform types: rugged sandstone hills and escarpment; low hills, rises and plains; and alluvial plains towards the intertidal fringes of the Bullo and Victoria rivers. These landform types support a range of habitats typical of northern Australia's tropical savannas including a variety of eucalypt communities, riparian zones, paperbark swamps, mangrove communities and saline coastal flats subject to tidal inundation.

\subsection{Field Data Sampling}

The field sampling was conducted over four years (2006 to 2009) and six sampling efforts, where access was achieved by helicopter and four wheel drive vehicle. A systematic approach was used to pre-select sites covering the geographic and environmental range across the study area using a Geographic Information System (GIS). To represent the various vegetation patterns, site selection was based on tonal variation, color and texture of the area as represented in 1:50,000 aerial photography and SPOT5 imagery. Disturbed areas (i.e., recent fire and grazing) were avoided.

Across the study area two site types were sampled: full floristic sites and less detailed sites, called "road notes" (Figure 1). Figure 1 illustrates field sites across Bullo River Station that were used for the multi-variate analysis of this study, including 392 sites and 957 plant species. At each full floristic site, 
all plant species present in a $20 \times 20 \mathrm{~m}$ quadrat were recorded with associated structural information (cover, height, and growth form across three strata). Cover was estimated as canopy cover (crowns treated as opaque) for the upper strata and projective foliage cover ( $\mathrm{PFC}$ - vertical projection of foliage only) for the mid- and ground strata. Mean height and range were measured for species greater than 2 $\mathrm{m}$ tall and visually estimated for those less than $2 \mathrm{~m}$ (for species greater than $1 \%$ cover). Road notes were qualitative and included a description of the dominant species and an estimate of the structural formation (including cover and height) for homogeneous vegetation patterns.

Figure 1. Distribution of full floristic and road note sites across Bullo River Station and the study area. Datum: GDA94, Coordinate System: Decimal Degrees 129.578-15.877, $129.825-15.597,129.469-15.534,129.688-15.7$.

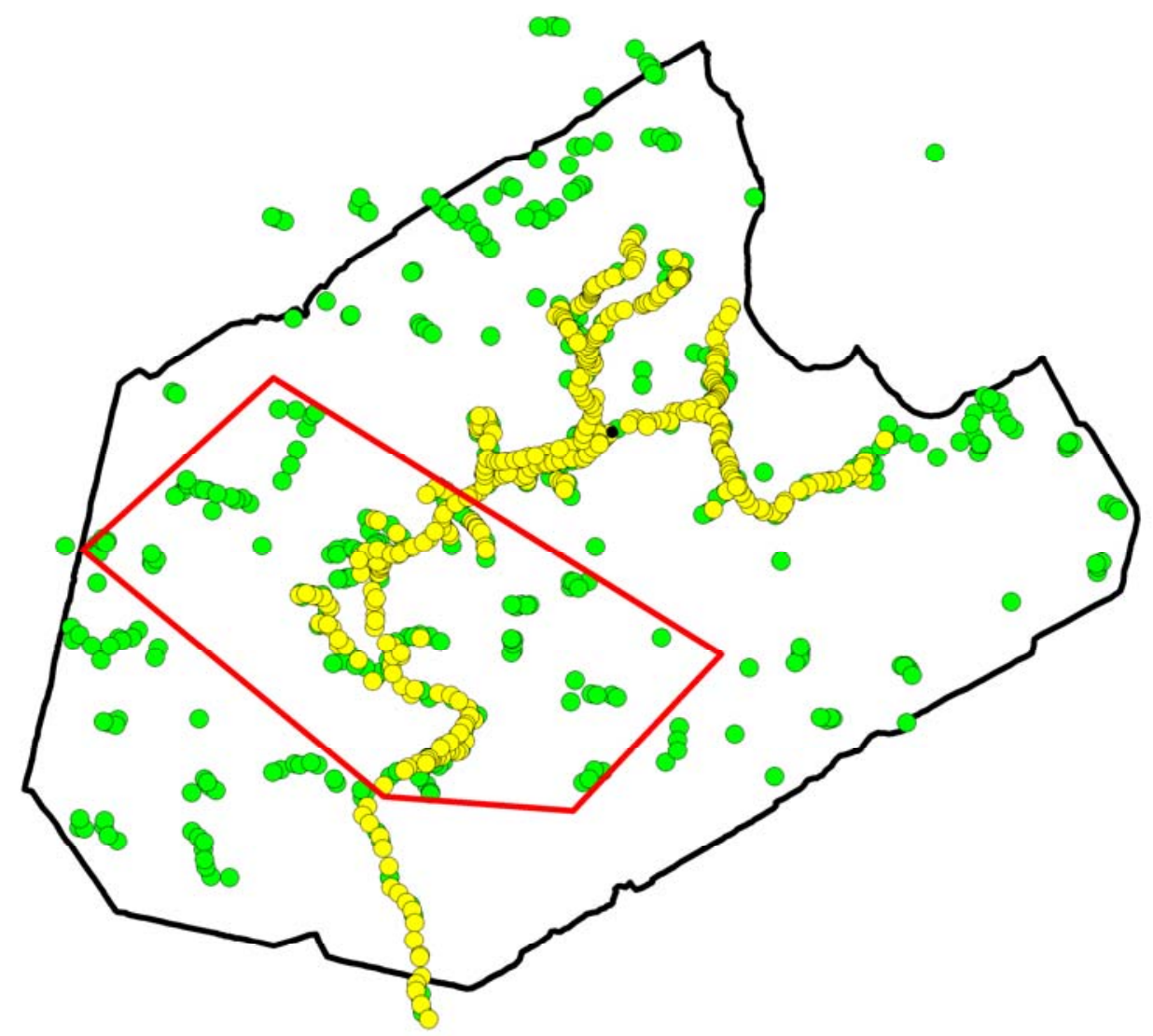

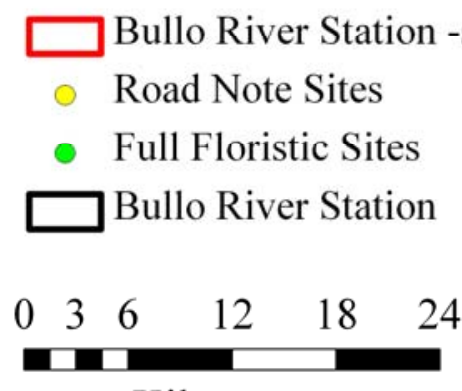

Kilometers

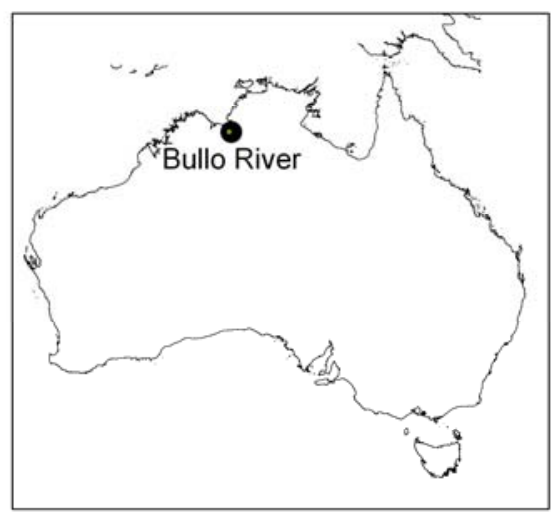

Within the study area, we sampled 137 full floristic sites and 104 road notes, 241 sites in total. Fifty percent of the field dataset were for training the seven mapping approaches and the remaining $50 \%$ 
were reserved for the accuracy assessment. Sampling intensity was dependent on accessibility, funding and resources. Detailed field sampling methods for the full floristic and road notes sites is provided by Lewis et al. [40] and is based on Australia's national standards for vegetation field sampling and vegetation classification $[40,41]$.

\subsection{Field Data Analysis and Vegetation Community Classification}

Multi-variate routines were applied to a subset (upper strata) of the full floristic dataset. Species contributing less than $0.1 \%$ cover were of low abundance and not diagnostic of the vegetation communities in the study and were removed for the analysis. A square root transformation was then applied to the upper strata dataset [40]. The most commonly used similarity coefficient (Bray-Curtis) was calculated and multi-dimensional scaling plots were used as a visual aid to remove 39 outlier sites. A combination of multi-variate analysis and intuitive classification identified 22 discrete and mappable vegetation communities across the study area (Appendix 1). The Similarity of Percentages (SIMPER) procedure was then used to discern species typical of the vegetation communities. SIMPER was also used to rank species in order of their relative contributions to determine community patterns for each floristic group [40]. Vegetation attributes were summarized to construct vegetation community descriptions [40] and were described using the National Vegetation Information System (NVIS) Information Hierarchy Level VI-sub-association, the highest level of detail floristically and structurally [42]. Finally, all field sites were assigned a vegetation community number prior to API, PBIA and GEOBIA.

\subsection{Image Data Acquisition and Pre-Processing}

Aerial photography was captured in May 2006 at a scale of 1:50,000 covering the extent of Bullo River Station (Figure 1). Differential Global Positioning System (GPS) centers and exterior orientation points from Applanix, color contact prints and photo scans at 15 micron resolution were also sourced. Every second digital aerial photograph was ortho-rectified using an exterior orientation method. Eight fiducial points were selected with a root mean square error of below 0.10 units. The output coordinate system was Geocentric Datum of Australia (GDA94), Map Grid of Australia (MGA52) eastings/northings at a scale of 1:50,000 (0.00002) and cell size $2 \times 2 \mathrm{~m}$ pixels using a nearest neighbor algorithm. The ortho-rectified aerial photos were mosaiced and color balanced with a blue haze filter [43].

The SPOT5 (10 m pixels) and Landsat5 TM (25 m pixels) scenes were also captured in May 2006 and supplied by Geoscience Australia and Geoimage respectively. The scenes were geometrically corrected to minimize distortions by using 24 ground control points. The SPOT5 imagery was ortho-rectified by Geoscience Australia and the Landsat5 TM scene was geometrically corrected using a standard technique developed by the Queensland Government Remote Sensing Centre (http://www.derm.qld.gov.au/ slats/index.html).

\subsection{Training Areas and Ancillary Data}

Training areas were created from $50 \%$ of the field data full floristic and road note sites. A systematic method was used to differentiate which field sites to use for the classification of the API, 
PBIA and GEOBIA approaches, and which ones for the accuracy assessment. Odd number sites were selected for the classifications and even site numbers for the accuracy assessment. There were two vegetation communities (13 and 30) which did not have field sites for the accuracy assessment, thus additional training areas were delineated based on interpreter knowledge of the study area. These communities were uncommon and small in extent across the study; therefore were under-sampled.

Four ancillary datasets were used in the integrated PBIA, NN-GEOBIA and step-wise GEOBIA approaches, including NDVI, DEM, DEM-derived slope model, and the 1:250,000 hydrology layer. The NDVI was calculated for Landsat5 TM and SPOT5 multi-spectral scenes according to the equation NIR-Red/NIR+Red, where NIR and R are the pixel values for the Near-Infrared and Red bands, respectively. The DEM was acquired through the Australian Defence Force as a $30 \times 30 \mathrm{~m}$ post spacing, $10 \mathrm{~m}$ contour file and currency 1990-1994. These ancillary datasets were subset to the study area. The hydrology polyline shapefile was sourced from the Water Resources Survey of Bullo River Station [44]. From the original hydrology dataset, two shapefiles were produced by buffering the major rivers and creeks at $80 \mathrm{~m}$, and minor creeks at $30 \mathrm{~m}$ to capture the extent of the two riparian vegetation communities present in the study area (21 and 4).

\subsection{Classification Methods}

The cost-effectiveness of seven vegetation community mapping approaches were assessed, including: (1). aerial photography interpretation, (2). pixel-based image-only classification, (3). pixel-based integrated classification, (4). object-based image-only nearest neighbor classification, (5). object-based integrated nearest neighbor classification, (6). object-based image-only step-wise classification, and (7). object-based integrated step-wise classification. The first approach was applied to 1:50,000 aerial photography and the remaining ones (approaches 2 to 7) to both SPOT5 and Landsat5 TM multi-spectral data. The integrated approaches incorporated ancillary data; whereas the image-only approaches only used the image datasets. Field data were used for each approach, 50\% for the classification processes and the remaining 50\% for the accuracy assessment. Two spatial scale maps $(1: 25,000$ and 1:100,000) were generated for each approach and image dataset.

\subsubsection{Aerial Photography Interpretation}

The aerial photography stereo pairs were examined under a stereoscope to delineate vegetation communities. Line-work was digitized as a polyline shapefile (GDA94, decimal degrees) using the mosaic as an interpretive base in a GIS. The spatial scale was set to 1:10,000 for line-work digitizing. The polyline dataset was smoothed using a smooth polylines algorithm and converted to a polygon shapefile [43]. Preliminary map attributes were assigned to the polygons of the original 1:10,000 polyline dataset and updated once the final vegetation community groups were determined based on 76 full floristic and 50 road notes and visual interpretation. Topography was also evaluated to define landform and land surface characteristics. Polygons less than 0.25 ha were eliminated to create the $1: 25,000$ thematic map and 4 ha for 1:100,000 [43]. 


\subsubsection{Pixel-Based Image Analysis}

Two pixel-based methods were applied to the Landsat5 TM and SPOT5 image datasets: image-only approach (image and field data), and integrated approach using ENVI ${ }^{\circledR}$ software. The integrated approach combined image data with field data, and various combinations of ancillary data, including: (1). DEM only, (2). DEM and NDVI, (3). DEM and slope, (4). DEM, slope and NDVI, and (5). DEM, slope and hydrology. Combining the datasets involved layer stacking, with the exception of the hydrology dataset. The hydrology dataset was used in the classification process by assigning vegetation communities 4 and 21 to the riparian areas from the hydrology map. A supervised Maximum Likelihood Classifier (MLC) was applied to the Landsat5 TM and SPOT5 for the pixelbased image-only and integrated approaches. MLC is one of the most widely used image classification algorithms [11,15,34,45-48] and was therefore selected for the PBIA component of this study.

The classification results were smoothed using a majority filter $(3 \times 3$ kernel $)$. Two vegetation community maps were generated at 1:25,000 and 1:100,000 spatial scales, where polygons less than 0.04 and 0.25 ha respectively were eliminated. Since ENVI MLC classification auto generates its own class numbers, these classes had to be relabeled to reflect the 22 communities on the four resultant maps prior to accuracy assessment [49].

\subsubsection{Object-Based Image Analysis}

Four object-based approaches were applied to the Landsat5 TM and SPOT5 multi-spectral image datasets to map 22 vegetation communities using eCognition ${ }^{\circledR}$ software, including:

(1) an image-only NN classification (image data and training areas),

(2) an integrated NN classification (image and ancillary data and training areas)

(3) an image-only step-wise classification (image data),

(4) an integrated step-wise classification (image and ancillary data).

Segmentation

Multi-resolution segmentations were applied to the Landsat5 TM and SPOT5 image datasets for the four object-based approaches. For the NN classifications we used one level of segmentation, called level one, segmented after incorporating a shapefile including the training areas (named test/training area (TTA) mask). For the step-wise classifications three hierarchical levels of segmentation were used to obtain contextual information and were called levels one, two and three. Thus, level one in the step-wise approaches was used for identifying landform patterns, level two was used to segment homogeneous features across the rises, low hills and hills, and the final classification of vegetation communities was carried out in level three aided by the information contained in levels one and two [50].

Nearest Neighbor Classifications

Training areas were selected as samples once the Landsat5 TM and SPOT5 image datasets were segmented, the. Samples were manually selected based on the discrete objects from the 241 training areas representing the 22 vegetation communities. The 22 vegetation communities were incorporated 
in the class hierarchy for both NN classifications (image-only and integrated). The object-features used for the image-only NN classification included the mean and standard deviation (SD) of all image layers. For the integrated NN classification, the feature space also included the mean and SD of all the image layers, plus the mean and SD of the NDVI, DEM and slope model. The GEOBIA NN classification algorithm was applied to level 1 and considered all vegetation communities. The minimum membership function was set to 0 [50].

Image-only Step-Wise Classification

The Landsat5 TM and SPOT5 images were segmented at three levels to capture the diversity of vegetation communities across the study area. At level one, the landform patterns were captured, including the riparian communities, using a range of object features, such as band ratios and layer values, and class-related features, including relations to neighboring objects. The landform patterns were incorporated into the class hierarchy as parent classes, including alluvial plains, plains and rises, low hills and hills, slope and riparian [50].

The second step captured the homogeneous vegetation communities which occurred on the plains and rises, and low hills and hills in level two. The objects classified at level two also included the riparian areas that had high vegetative reflectance and objects that were small (linear and compact). Finally, level three, the highest level of detail, was used to classify the vegetation communities that were small in extent and of heterogeneous nature using a variety of object features including layer values, geometry and position, and customized features, and class related features including relations to neighbor objects, relations to super objects and relations to classification [50].

Integrated Step-Wise Classification

The integrated step-wise classifications incorporated the ancillary datasets into the classification processes. Similar to the image-only step-wise classification, objects at level one captured the landform patterns including alluvial plains, plains, rises and low hills, hills, slope and riparian. The two riparian communities (4 and 21) were first classified based on the thematic attributes of the two hydrology shapefiles. The landform patterns were classified based on the mean values of the DEM. The slope model was used to classify the vegetation communities that occur in areas with high slope across the rises and low hills, and hills. At level two, vegetation communities occurring across the plains, rises and low hills, and hills were classified based on a range of object and class-related features, similar to the image-only step-wise classification [50]. Vegetation communities across the alluvial plains were classified at level three. A final step in the classification process was the refining of other vegetation communities classified at previous levels, using contextual information.

\subsection{Cost-Effectiveness}

Two components were used for the cost-effectiveness: accuracy assessment which was based on overall accuracy and cost associated with each mapping approach.

Confusion matrices were calculated for the 28 resultant vegetation community maps using ENVI ${ }^{\circledR}$ software for the accuracy assessment component. The training areas reserved for the accuracy 
assessment were used to match with the classes in the classified images. Overall accuracy was computed and results analyzed for each approach, image dataset and spatial scale map.

The cost incorporated four main components: field data acquisition and preparation; image data acquisition and preparation; image classification; and accuracy assessment. The cost-effectiveness evaluation assumed hardware and software requirements were already in place. The cost and time associated with each component and subcomponent were documented in preparation for the costeffectiveness evaluation. Table 1 outlines how the cost and time were estimated for each component/subcomponent and mapping approach.

Table 1. Components and subcomponents used for estimating the cost and time associated with each mapping approach.

\begin{tabular}{ccc}
\hline Component & Subcomponent & Detailed Costs and Time Invested \\
\hline & Field sampling* & $\begin{array}{c}\text { Working hours, staff salaries, staff } \\
\text { travel allowance, helicopter hire cost } \\
\text { (wet rate), vehicle lease cost, fuel cost }\end{array}$ \\
(1) Field data acquisition & Plant identification and databasing*
\end{tabular}
and preparation*

Working hours, staff salaries

Multi-variate analysis and vegetation classification*

\begin{tabular}{lcc}
\hline $\begin{array}{l}\text { (2) Image data acquisition } \\
\text { and preparation }\end{array}$ & Image acquisition & $\begin{array}{c}\text { Working hours, staff salaries, image } \\
\text { cost }\end{array}$ \\
\hline & Image pre-processing & Working hours, staff salaries \\
\hline & API linework & \\
& API attribution \\
(3) Image Classification & PBIA training & \\
& PBIA classification & Working hours, staff salaries \\
& GEOBIA segmentation & \\
\hline (4) & Accuracy Assessment* & GEOBIA classification \\
\hline & Accuracy assessment* & Working hours, staff, salaries \\
\hline
\end{tabular}

\section{Results and Discussion}

\subsection{Vegetation Communities}

Twenty two vegetation communities were described for the study area (Appendix 1), based on the field data sampling, multi-variate analysis and vegetation classification. Some vegetation communities were more extensive than others. The most common and widespread vegetation community was Eucalyptus tectifica low woodland (1). This community occurred across a range of landform patterns and substrates, predominantly plains, rises and low hills in association with community 7. Corymbia dichromophloia low open woodland (2) was widespread on a range of sandstone landform patterns, mainly low hills and hills. Acacia spp., Grevillea spp., Gardenia spp. tall sparse shrubland (22) was also extensive and characteristic of broken sandstone plateaus and hills. Eucalyptus phoenicea low 
open woodland (10) was another widespread community, generally in association with community 22 and 2. Eucalyptus miniata mid open woodland (6) existed as three forms, an influence of substrate and landform. A typical form was on the plateaux, a second form occurred on rugged sandstone hill slopes and the third was on heavier soils adjacent to drainage lines on the alluvial plains.

The major river system (Bullo River) and its perennial tributaries were dominated by Melaleuca leucadendra mid woodland (21), also including significant paperbark swamps not associated with the riparian areas. The second riparian community (4) was dominated by Lophostemon grandiflorus mid woodland on ephemeral stream channels across plains, rises, low hills, hills and plateaux, usually in association with community 21. On the drainage depressions, Corymbia polycarpa mid open woodland (11) and Melaleuca viridiflora low woodland (20) were either discrete or intergraded. Adjacent to drainage depressions and major riparian systems were relict levees dominated by Corymbia bella mid woodland (3) and neighbouring on the plains was Corymbia foelscheana mid woodland (18).

The community dominating the slopes was Buchanania obovata and Terminalia latipes low open woodland (12). Also common on scarps and the heads of gullies hills was Xanthostemon paradoxus, Pouteria sericea, and Ziziphus quadrilocularis mid woodland (28), dry vine thicket. There were a number of less extensive communities, largely including on permanent springs (13) and swamps dominated by either tussock grasses (8) or sedges (30). Eucalyptus brevifolia low open woodland (15) and Melaleuca sericea low open woodland (16) were confined to hills in the south-west corner of the study area on a distinctive geology type [40].

\subsection{Cost-Effectiveness}

The results of the cost-effectiveness assessment are divided into: (1). accuracy assessment which was based on overall accuracy and defined as the 'benefit', and (2). the cost and time associated with the approaches and image datasets.

\subsubsection{Accuracy Assessment}

The number of sites selected for map attribution (API)/classification training (PBIA and GEOBIA) and accuracy assessment had the same number of sites and were equal in area $\left(\mathrm{km}^{2}\right)$ for the majority of vegetation communities. The number of sites per vegetation community for the accuracy assessment ranged from one to 27, with an average of six. The spatial distribution of field sites (Figure 1) shows that they were not randomly distributed throughout the study area, but the majority were confined to the main access track and non-gazetted tracks. However, to sample the required number of sites for quantitative accuracy assessment, field sampling costs would double, which was unaffordable. Nonetheless, the total cost of field sampling was AU\$120,000, including staff salaries, travel allowance, and vehicle costs. Helicopter hire (wet rate) alone exceeded AU\$28,000.

API presented the highest overall accuracy with 66.67\% (Figure 2) [43]. On average, PBIA presented the lowest overall accuracies which ranged from 30 to 53\% [49]. For both OBIA and PBIA, the dataset demonstrating the highest overall accuracies was the Landsat5 TM with DEM and slope integrated, and at the 1:25,000 spatial scale. For GEOBIA, the overall accuracy ranged from 32\% for the NN image-only Landsat5 TM classification to 53\% for the integrated step-wise classification applied to the SPOT5 image [50]. 
The results of the PBIA image-only and integrated approaches indicate that the incorporation of ancillary data considerably improved overall classification results. The incorporation of a DEM and slope model improved classification results for both image datasets. Overall, any combination of image and ancillary data improved overall accuracy when compared to the image-only approach applied to Landsat5 TM and SPOT5. Other studies report that the incorporation of ancillary data improves classification results for a range of land cover and vegetation community mapping applications, and in urban areas [19-22,51,52]. The incorporation of the DEM and slope model improved the classification of the image-only approach by 10\% [50]. For both PBIA image-only and integrated approaches, Landsat5 TM gave higher overall accuracy results compared to SPOT5. This was attributed to the additional spectral information of Landsat5 TM, particularly its visible and mid-infrared bands, even though SPOT5 has a higher spatial resolution. This finding is consistent with other studies by Gibbes et al. [16] and Stickler et al. [18]. Similarly, with the GEOBIA approaches, the incorporation of ancillary data considerably improved overall classification accuracy for both the step-wise and the NN classifications, and for the two image datasets. The dataset presenting the highest overall accuracy for the NN classifications was SPOT5 with ancillary datasets integrated; a 10\% improvement to using the image data in isolation. When compared to Landsat5 TM, incorporating ancillary data increased the overall accuracy result by 3\%. For all GEOBIA approaches, SPOT5 gave higher overall accuracy results, on average, compared to Landsat5 TM. This finding was attributed to the higher spatial resolution of SPOT5. The NN classifications applied to Landsat5 TM and SPOT5 failed to depict the floristic detail of vegetation communities. The image-only step-wise classification displayed an improvement to the NN classifications. This was improved by $7 \%$ when the ancillary data was included in the integrated step-wise approach. The image dataset and technique illustrating the highest overall accuracy was the SPOT5 integrated step-wise classification.

In summary, it appears that the spectral information of the Landsat sensor compensated for its coarser spatial resolution in the PBIA approaches, which is consistent with findings by Stickler et al. [18]. Conversely, the higher spatial resolution of the SPOT5 compensated for the fewer spectral bands in the four GEOBIA approaches. The benefit of GEOBIA is the ability to use a combination of spectral and object-based information to build context into rulesets [53]; therefore, is not solely reliant upon spectral information alone, unlike PBIA. Gibbes et al. [16] also reports the benefits of using high resolution imagery, although the limitation is the cost and is also dependent on the research question. 
Figure 2. Overall accuracy for the seven vegetation community mapping approaches (aerial photography interpretation (API); pixel-based image analysis (PBIA) (integrated and image-only); geographic object-based image analysis (GEOBIA) (integrated and image only; nearest neighbor and step-wise)); applied to the three image datasets (aerial photography, Landsat5 TM and SPOT5), for two spatial scales (1:25,000 and $1: 100,000$ ).

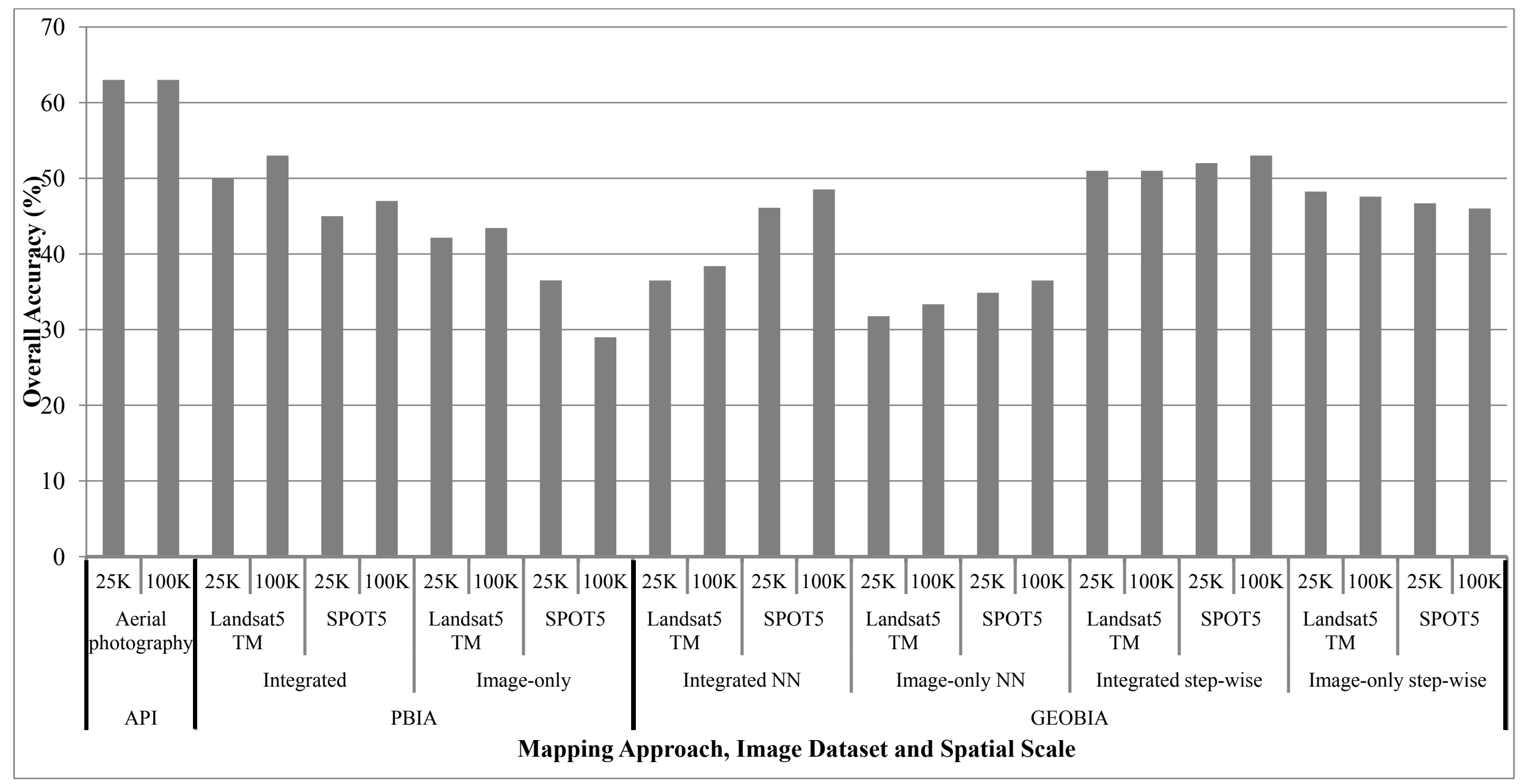


In terms of spatial scale, a slight difference was apparent in overall accuracy for all PBIA and GEOBIA techniques and image datasets. Appendix 2 contains 25 thematic maps for the seven mapping approaches, three image datasets and at the two spatial scales. On average, 1:100,000 thematic maps produced slightly higher accuracies. This result can be attributed to the spatial and attribute detail eliminated from the maps. Both API maps generated the same accuracy as none of the eliminate polygons intersected any validation field site. If additional sites were sampled for the accuracy assessment, the result may be different, although not significantly, given that 51 small polygons (less than 4 ha) were eliminated from a total 700 .

There are no formally published studies that provide a comparison of cost effectiveness using API, PBIA and GEOBIA that capture the floristic and structural components of vegetation communities. The majority of studies that do exist focus on capturing land cover which comprise very broad classes, fewer classes (14 or less), and minimal structural information. These studies show higher overall accuracies for GEOBIA compared to PBIA in a range of environments, including native vegetation to agricultural landscapes. In a northern Australia's tropical savanna, results showed a higher overall accuracy of the GEOBIA over PBIA, 78.5\% versus $69.5 \%$ respectively [54]. The results by Whiteside et al. [54] suggest that GEOBIA has potential as an alternative method (over per-pixel) approaches for extracting land cover information from medium to high resolution satellite imagery. This is consistent with findings within the literature [55-57]. However, in agricultural areas there was no significant difference in overall accuracy between GEOBIA and PBIA [58].

\subsubsection{Cost}

Four main cost components were documented and evaluated, including: field data acquisition and preparation; image data acquisition and preparation; image classification; and accuracy assessment. Two of the components were consistent for each approach, including the field data acquisition and preparation and the accuracy assessment. These components do not influence the cost-effectiveness comparison for the seven tested approaches, the three image datasets, or the two spatial scales. However, they are a major component of any vegetation community mapping project, irrespective of the approach, image dataset, and to a degree, spatial scale of the output thematic map. The importance of the field data sampling, plant identification, data basing, multi-variate analysis and vegetation classification is often not reported on in terms of cost and time. Thus, it is presented in this study to highlight the fact that it is one of the most labor-intensive and expensive steps in vegetation community mapping.

The results of the consistent cost components are presented in Table 2. The consistent component displaying the highest cost was field data acquisition and preparation, equating to AU\$324,710 (Australian dollars), while the accuracy assessment came to AU\$1,890 (100\% salaries). Field data acquisition and preparation is made up of three subcomponents including field sampling, plant identification and data basing, and multi-variate analysis and vegetation classification.

Of the three consistent subcomponents, plant identification and data basing was the most expensive and equated to AU\$201,700 (100\% salaries). This included sorting specimens to family and generic levels, identifying all specimens collected that were unable to be identified in the field, and data basing the plot sheets. The cost of plant identification would fluctuate based on botanical expertise, time of 
sampling (wet season versus dry season), and full floristic or dominant species inventories. A recent study indicates a full floristic inventory is not necessary for vegetation community mapping [40], thus this cost would be significantly reduced. This cost was followed by the field sampling, which totaled AU\$120,000, and included staff salaries (including on-costs and travel allowance) and vehicle costs (including helicopter hire, vehicle lease, maintenance and fuel). Helicopter hire (wet rate) alone was AU\$28,700. Increased field sampling is thought to increase overall accuracy, however, few studies have been undertaken to address this. Benson [59] found costs vary depending on the complexity of the vegetation and the aims of the project. For instance, local spatial scales $(1: 25,000)$ far exceeded the cost of regional surveys $(1: 100,000)$. The less labor-intensive and expensive consistent subcomponents were the multi-variate analysis and vegetation classification, which came to AU\$3,010 (100\% salaries).

Table 2. Consistent cost components for vegetation community mapping subcomponents, detailed cost and total cost in Australian dollars (AU\$).

\begin{tabular}{|c|c|c|c|}
\hline Component & Subcomponent & Detailed Cost (AU\$) & Total Cost (AU\$) \\
\hline \multirow{6}{*}{$\begin{array}{l}\text { Field data acquisition } \\
\text { and preparation }\end{array}$} & & Salaries*: 59,227 & \multirow{4}{*}{120,000} \\
\hline & Field samnling & Travel allowance: 15,746 & \\
\hline & Field sampling & Vehicle costs: 5,120 & \\
\hline & & Helicopter hire: 28,700 & \\
\hline & $\begin{array}{c}\text { Plant identification and } \\
\text { data basing }\end{array}$ & $\begin{array}{c}\text { Plant identification*: } 196,700 \\
\text { Data basing*: } 5,000\end{array}$ & 201,700 \\
\hline & $\begin{array}{l}\text { Multi-variate analysis and } \\
\text { vegetation classification }\end{array}$ & $\begin{array}{l}\text { Multi-variate analysis*: } 2,260 \\
\text { Vegetation classification*: } 750\end{array}$ & 3,010 \\
\hline \multirow[t]{3}{*}{ Accuracy assessment } & & $\begin{array}{l}\text { Generating training areas from } \\
\text { field data*: } 1,400\end{array}$ & \multirow[t]{2}{*}{1,890} \\
\hline & & Accuracy assessment*: 490 & \\
\hline & & TOTAL & 326,600 \\
\hline
\end{tabular}

The remaining two components including image data acquisition and preparation, and image classification are relevant to the cost-effectiveness comparison of the seven mapping approaches. Figure 3 illustrates the costs associated with the image data acquisition and preparation of the three image datasets. Pre-processing of the 1:50,000 aerial photography equated to AU\$611, SPOT5 AU\$216 and Landsat5 TM AU\$36. The cost of image acquisition was the highest for the aerial photography (AU\$24,000), followed by SPOT5 (AU\$10,000) and Landsat5 TM (AU\$760).

Figure 4 demonstrates the cost associated with the image classification component. The API is the most labor-intensive, thus the most expensive approach equating to AU\$11,200 (100\% salaries). The least expensive approach was the PBIA image-only approach, with AU\$140 (100\% salaries). The GEOBIA approaches ranged between AU\$420 and AU\$3,325. The integrated step-wise classification was the most expensive GEOBIA approach, almost eight times more expensive than the NN classification. This large difference in cost was due to the difference in hours of work required to set up the step-wise ruleset. Although setting up a step-wise rule set from scratch is very demanding in terms of hours, once this has been set up it can be easily adapted to adjacent areas. In that case, the total amount of time invested would be considerably reduced. 
Figure 3. Costs in Australian dollars (AU\$) associated with the image data acquisition and preparation component, including its two sub-components (image acquisition and image pre-processing) for the three image datasets (aerial photography, SPOT5 and Landsat5 TM).

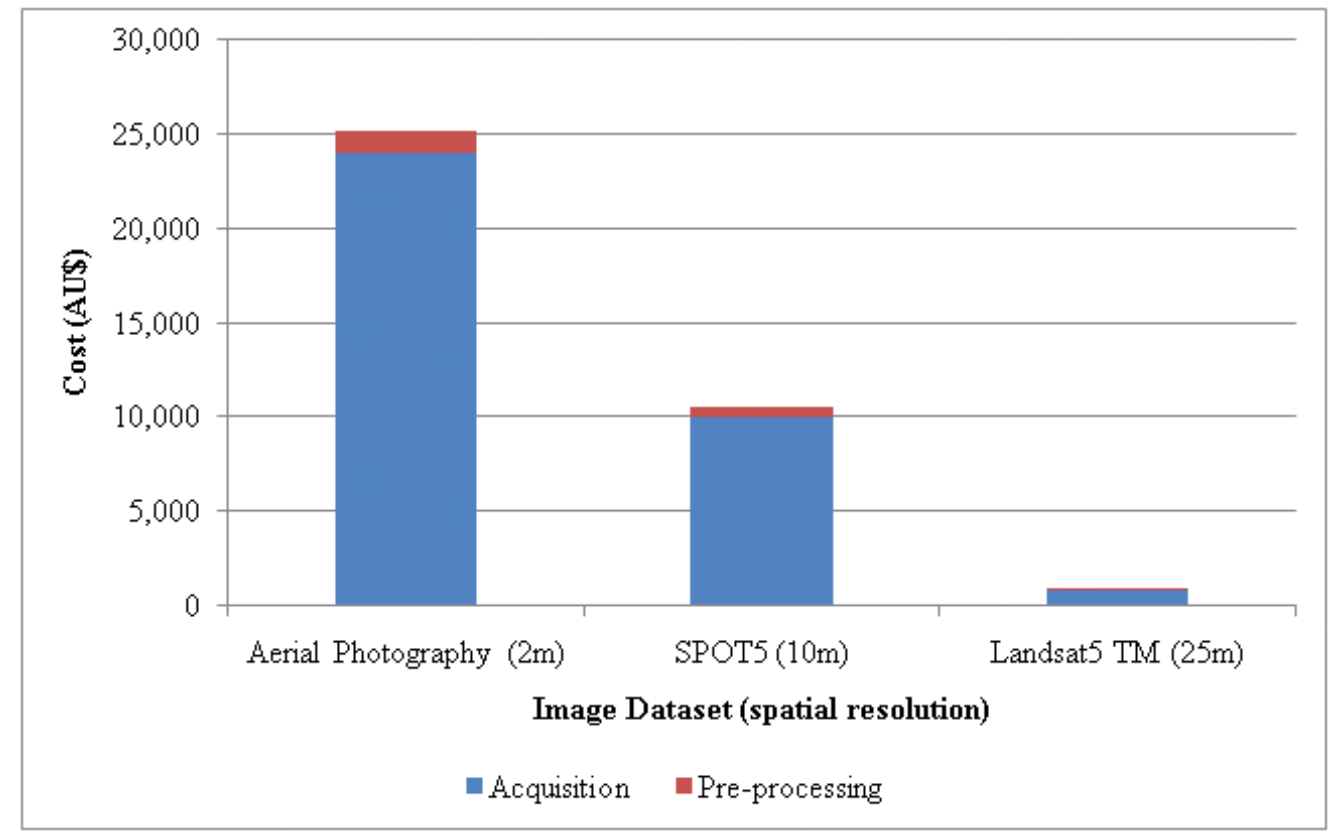

Figure 4. Costs in Australian dollars (AU\$) associated with the classification component for the seven mapping approaches including (1). aerial photography interpretation, (2). pixelbased image-only classification, (3). pixel-based integrated classification, (4). object-based image-only NN classification, (5). object-based integrated NN classification, (6). object-based image-only step-wise classification, and (7). object-based integrated step-wise classification.

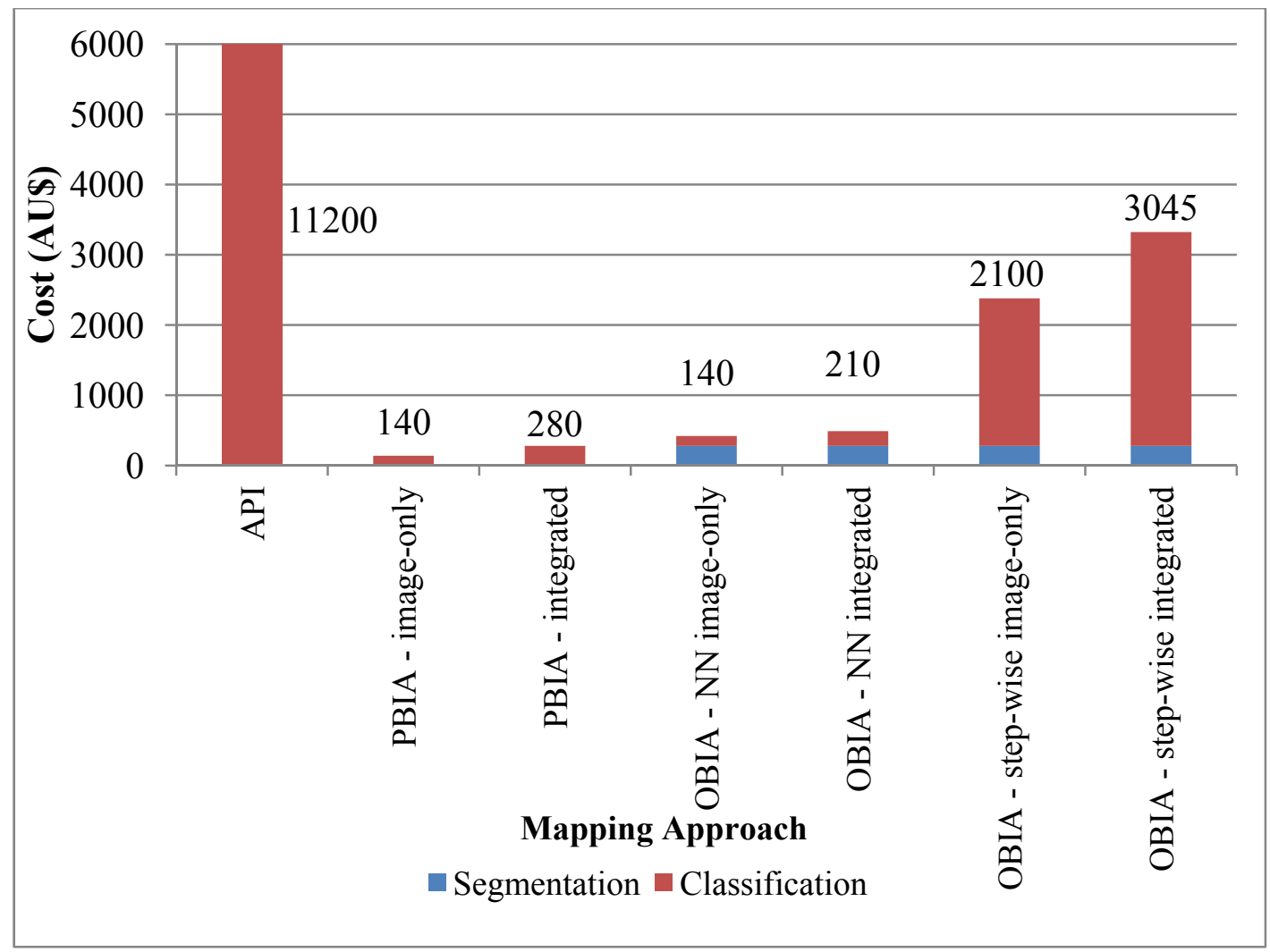


Figure 5 summarizes the results obtained in the cost-effectiveness analysis for the seven approaches based on the four cost components. Figure 6 illustrates the highest overall accuracy results for the seven approaches. Figures 5 and 6 are based on the following image datasets and spatial scales for the seven mapping approaches:

(1) API: 1:50,000 aerial photography mosaic at 1:100,000,

(2) PBIA image-only: Landsat5 TM at 1:100,000,

(3) PBIA integrated: Landsat5 TM (DEM and slope) at 1:100,000,

(4) GEOBIA NN image-only: SPOT5 at 1:100,000,

(5) GEOBIA NN integrated: SPOT5 (DEM and slope) at 1:100,000,

(6) GEOBIA step-wise image-only: SPOT5 (contextual information) at 1:100,000, and

(7) GEOBIA step-wise integrated: SPOT5 (DEM, slope and contextual information) at 1:100,000.

Figure 5. Distribution of the total costs, in Australian dollars (AU\$), for the seven mapping approaches. Cost for each component (field data acquisition and preparation; image data acquisition and preparation; image classification, and accuracy assessment) is presented in a different color. Note that, in order to represent different orders of magnitude, the scale used for each cost component is different (color and scale used for each cost component is specified in the legend).

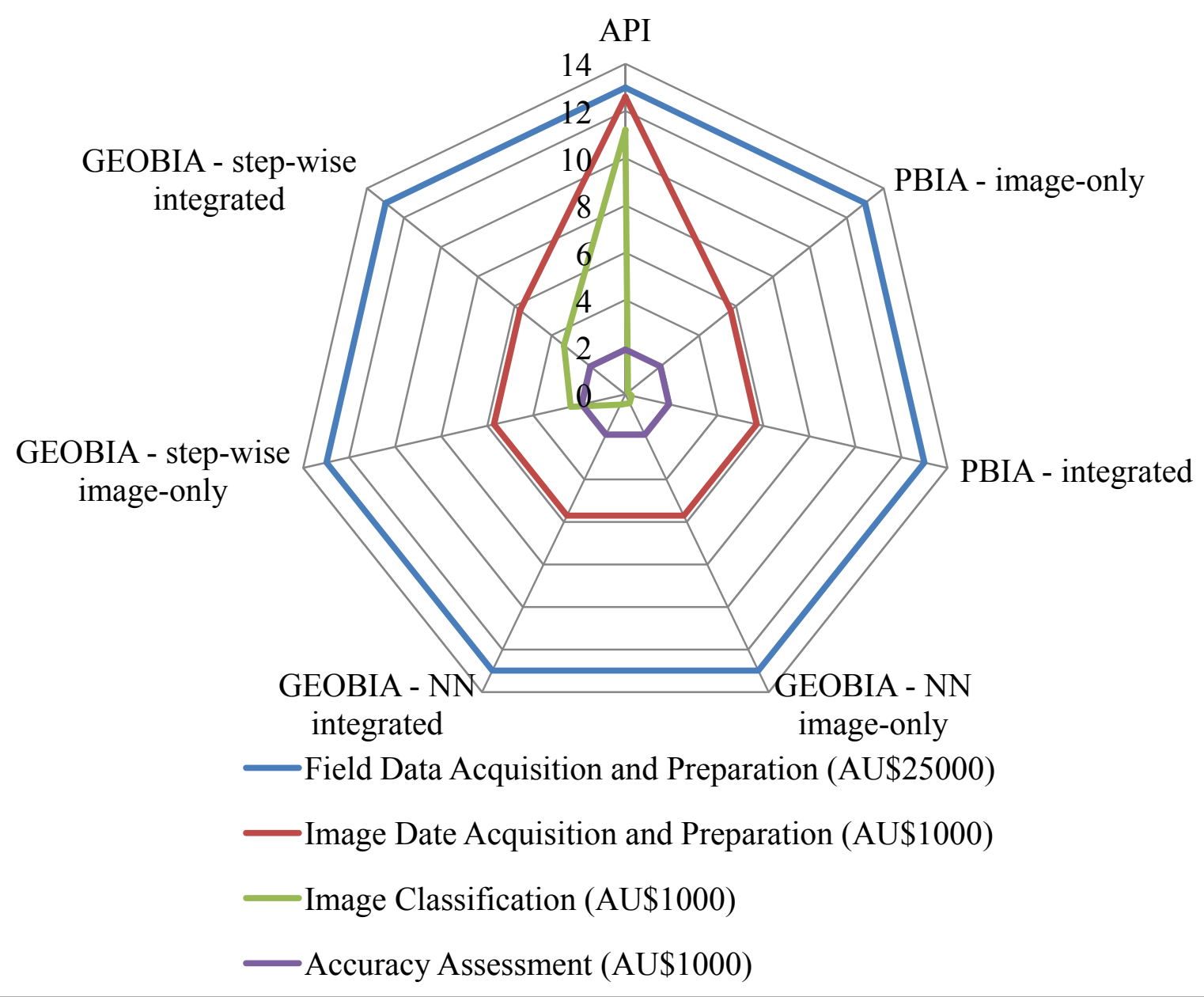


Taking into account the four cost components, API is the most expensive and labor-intensive mapping approach and also has the highest overall accuracy. The total cost was AU\$388,180. PBIA was the cheapest mapping approach (AU $\$ 338,000)$; however had the lowest average overall accuracy for the image-only classification (37\%). The cost of the GEOBIA approaches ranged from AU\$338,000 (NN classifications) to AU\$341,000 for the step-wise integrated classification, which also displayed the highest overall accuracy of the GEOBIA approaches. There is a correlation with cost and accuracy in that the lower the cost of classification approach, the lower the overall accuracy.

Training of the analyst was required for the PBIA classification and involved seven hours. More training was required for the GEOBIA segmentation and classification. The total number of hours spent on analyst training was 61 and included a five-day training course, online tutorials and one-on-one training with experienced staff. No training was required for the analyst to undertake the API mapping approach. However, training and experience would be required in such a study if an analyst had no experience with API. Training should be factored into future mapping programs if staff are inexperienced with any of the components.

Figure 6. Highest overall accuracy results for the seven mapping approaches tested.

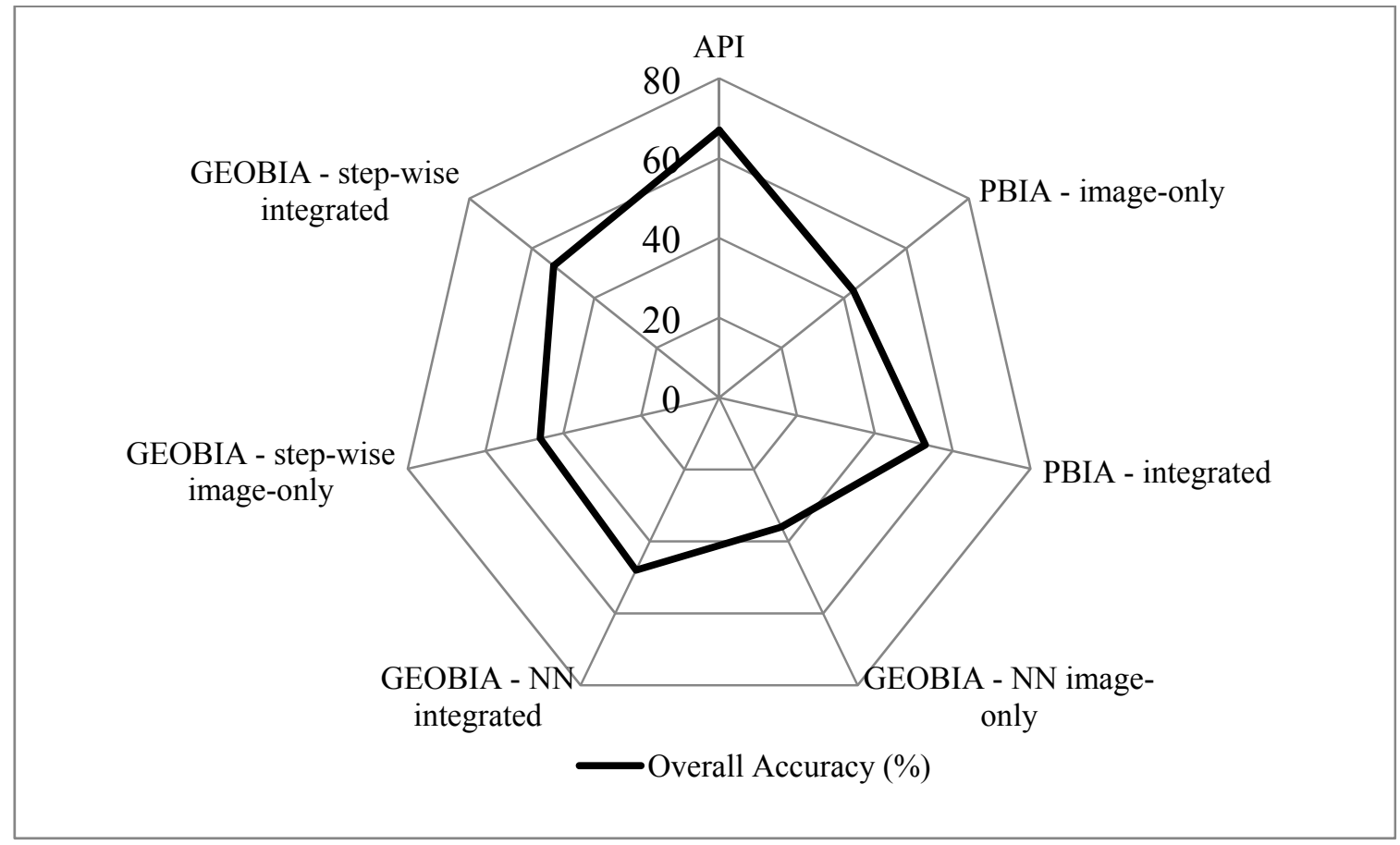

There have been very few cost-effectiveness studies undertaken on vegetation community mapping programs around the globe. There are, however, a number of examples from Australia, where Neldner [60] undertook a study highlighting the value and utility of vegetation survey and mapping programs in Queensland, and suggested costs can be calculated based on time, staff, transport, data and laboratory analysis, and publication costs. The field work component was found to account for $60 \%$ to $70 \%$ of total costs. This result is consistent with the findings of this study where the field survey component was the most expensive and labor-intensive. Other land resource mapping programs across northern Australia have been calculated for a number of surveys, yet nothing has been formally documented.

In south eastern Australia, cost estimates have been tested in pilot vegetation surveys across various 1:100,000 map sheets in the Murray-Darling Basin [59]. Costing was based on API methods and 
included costs of field survey, botanical support, vehicle hire, aerial photograph digitizing and attributing and the cost of each photo. The study found costs vary depending on the complexity of the vegetation and the aims of the project. For instance, local spatial scales $(1: 25,000)$ far exceeded the cost of regional surveys $(1: 100,000)$. Studies have acknowledged that the benefit to cost ratio of vegetation surveys is approximately 40:1 [59]. The benefits of vegetation surveys and maps are numerous largely providing a basis for land use planning, environmental impact assessment, community participation, research and teaching, conservation, fauna distribution, forestry and military uses, amongst others [60].

The selection of approach to map vegetation communities is dependent on budget, resources, staff expertise, imagery and ancillary dataset availability, time constraints (deadlines) and the required degree of accuracy. These constraints are also influenced by the perceived application of an output vegetation community map. Thus, to generate the most accurate map, based on this study, aerial photography interpretation is the most appropriate method, although sufficient funds and adequate timeframe is required. For projects with limited timeframes, low budgets and a perceived accuracy of less than 55\%, PBIA applied to Landsat5 TM would be acceptable. If, however, experienced staff were available, GEOBIA presents an alternative to aerial photography interpretation, using either high or moderate spatial resolution imagery. The results of this study suggest that GEOBIA is a potential technique to capture the floristic component and associated structural elements of vegetation in tropical savanna vegetation communities using the step-wise approach.

\section{Conclusions}

This study compares the cost-effectiveness of mapping vegetation communities using: (1). seven mapping approaches, (2). three image datasets at varying degrees of spatial resolution, and (3). two spatial scales including 1:25,000-property management scale and 1:100,000-regional scale. The seven approaches included: (1). aerial photography interpretation, (2). pixel-based image-only classification, (3). pixel-based integrated classification, (4). object-based image-only NN classification, (5). object-based integrated NN classification, (6). object-based image-only step-wise classification, and (7). object-based integrated step-wise classification. The approaches were applied to 1:50,000 aerial photography (approach 1), and SPOT5 and Landsat5 TM multi-spectral data (approaches 2 to 7). Overall accuracy ranged from 28 to $67 \%$ for the seven approaches. Aerial photography presented the highest overall accuracy (67\%) for the 1:25,000 spatial scale map, and the image-only pixel-based approach applied to Landsat5 TM at 1:25,000 demonstrated the lowest (28\%). Of the four main cost components, the most labor-intensive was the field data acquisition and preparation, followed by image data acquisition and preparation. The cost of image acquisition was the highest for the aerial photography, followed by SPOT5 and Landsat5 TM. The accuracy assessment component was the least expensive. Overall, the API was the most labor-intensive, thus most expensive approach. The least expensive approach was the PBIA image-only classification. Of the four GEOBIA approaches, the integrated step-wise classification was the most expensive. When the four components are factored into the total cost for the seven mapping approaches, API remains the most expensive and labor intensive approach, and also has the highest accuracy. PBIA was the cheapest mapping approach, however, had the lowest overall accuracy. Of the four GEOBIA approaches, the NN image-only gave 
the lowest overall accuracy and was the cheapest approach. The GEOBIA step-wise integrated classification displayed the highest overall accuracy and highest cost. There was a definite correlation with overall accuracy and associated costs for the seven mapping approaches, where an increase in overall accuracy reflected an increase in total costs.

Suggestions to improve this work include the use of a fuzzy accuracy assessment to compensate for continuous variables like vegetation communities. The application of fuzzy rules to this study would strengthen the results of vegetation communities with poor separability and similar landscape position. WorldView-2 imagery, comparable in the number of spectral bands to Landsat5 TM and a much higher spatial resolution to SPOT5 (8-band multispectral and a spatial resolution of $46 \mathrm{~cm}$ ), would be of interest in this study region and expected to yield better cost-effective results. An extension of the cost-effectiveness evaluation could potentially include set-up costs such as hardware and software.

\section{Acknowledgments}

This study is a component of a $\mathrm{PhD}$ undertaken through the University of Queensland. The Department of Natural Resources, Environment, The Arts and Sport of the Northern Territory Government is thanked for logistical support and funding. Numerous colleagues are acknowledged for their involvement in field data collection Ian Cowie, John Westaway, Dale Dixon, Raelee Kerrigan, Benjamin Stuckey, Laura Proos, Jason Hill, Graeme Owen and Bart Edmeades. Special thanks to the owners and managers of Bullo River Station, Franz and Marlee Ranacher. Nicholas Cuff, Grant Staben, Chris Roelfsema and Karen Joyce are acknowledged for technical support. Damian Milne is thanked for commenting on the manuscript and the anonymous reviewers for providing constructive comment on the manuscript.

\section{References}

1. Thackway, R.; Lee, A.; Donohue, R.; Keenan, R.J.; Wood, M. Vegetation information for improved natural resource management in Australia. Landsc. Urban Plan. 2007, 79, 127-136.

2. Weiers, S.; Bock, M.; Wissen, M.; Godela, R. Mapping and indicator approaches for the assessment of habitats at different scales using remote sensing and GIS methods. Landsc. Urban Plan. 2004, 67, 43-65.

3. Kerr, J.; Ostrovsky, M. From space to species: Ecological applications for remote sensing. Trends Ecol. Evol. 2003, 18, 299-305.

4. Wulder, M.A.; Franklin, S.E. Remote Sensing of Forest Environments: Concepts and Case Studies; Kluwer Academic Publishers: Norwell, MA, USA, 2003.

5. Franklin, S.E. Remote Sensing for Sustainable Forest Management; Lewis Publishers, CRC Press LLC: Boca Raton, FL, USA, 2001.

6. Mehner, H.; Cutler, M.; Fairbairn, D.; Thompson, G. Remote sensing of upland vegetation: the potential of high spatial resolution satellite sensors. Glob. Ecol. Biogeogr. 2004, 13, 359-369.

7. Lees, B.G.; Ritman, K. Decision-tree and rule-induction approach to integration of remotely sensed and GIS data in mapping vegetation in disturbed or hilly environments. Environ. Manage. 1991, 15, 823-831. 
8. Lu, D.; Weng, Q. A survey of image classification methods and techniques for improving classification performance. Int. J. Remote Sens. 2007, 28, 823-870.

9. Miller, J.; Franklin, J.; Aspinall, R. Incorporating spatial dependence in predictive vegetation models. Ecol. Model. 2007, 202, 225-242.

10. Goetz, S.J.; Wright, R.K.; Smith, A.J.; Zinecker, E.; Schaub, E. IKONOS imagery for resource management: Tree cover, impervious surfaces, and riparian buffer analyses in the mid-Atlantic region. Remote Sens. Environ. 2003, 88, 195-208.

11. Koch, B.; Ivitis, E.; Jochum, M. Forest classification with eCognition and ERDAS expert classifier: Object-based versus Pixel-based. GIM Int. 2003, 17, 12-15.

12. Flanders, D.; Hall-Beyer, M.; Pereverzoff, J. Preliminary evaluation of eCognition object-based software for cut block delineation and feature extraction. Can. J. Remote Sens. 2003, 29, 441-452.

13. Laliberte, A.; Fredrickson, E.; Rango, A. Combining decision trees with hierarchical object-oriented image analysis for mapping arid rangelands. Photogramm. Eng. Remote Sensing 2007, 73, 197-207.

14. Ivits, E.; Koch, B.; Blaschke, T.; Waser, L. Landscape Connectivity Studies on Segmentation Based Classification and Manual Interpretation of Remote Sensing Data. In Proceedings of eCognition User Meeting, Munich, Germany, 28-30 October 2002.

15. Wang, L.; Sousa, W.P.; Gong, P. Integration of object-based and pixel-based classification for mapping mangroves with IKONOS imagery. Int. J. Remote Sens. 2004, 25, 5655-5668.

16. Gibbes, C.; Adhikari, S.; Rostant, L.; Southworth, J.; Qiu, Y. Application of object based classification and high resolution satellite imagery for savannah ecosystem analysis. Remote Sens. 2010, 2, 2748-2772.

17. Mumby, P.; Edwards, A. Mapping marine environments with IKONOS imagery: Enhanced spatial resolution can deliver greater thematic accuracy. Remote Sens. Environ. 2002, 82, 248-257.

18. Stickler, C.; Southworth, J. Application of multi-scale spatial and spectral analysis for predicting primate occurance and habitat associations in Kibale National Park, Uganda. Remote Sens. Environ. 2008, 112, 2170-2186.

19. Gould, W. Remote sensing of vegetation, plant species richness, and regional biodiversity hotspots. Ecol. Appl. 2000, 10, 1861-1870.

20. Lewis, M. Species composition related to spectral classification in an Australian spinifex hummock grassland. Int. J. Remote Sens. 1994, 15, 3223-3239.

21. Lewis, M. Numeric classification as an aid to spectral mapping of vegetation communities. Plant Ecol. 1998, 136, 133-149.

22. Ozesmi, S.; Bauer, M. Satellite remote sensing of wetlands. Wetlands Ecol. Manage. 2002, 10, 381-402.

23. Richards, J.; Landgrebe, D.; Swain, P. A means of utlising ancillary information in multispectral classification. Remote Sens. Environ. 1982, 12, 463-477.

24. Tunstall, B.; Harrison, B.; Jupp, D. Incorporation of Geographical Data in the Analysis of Landsat Imagery for Land-Use Mapping-A Case Example. In Proceedings of Australasian Remote Sensing Conference, Adelaide, Australia, August 1987.

25. Rogan, J.; Franklin, J.; Roberts, D. A comparison of methods for monitoring multitemporal vegetation change using Thematic Mapper imagery. Remote Sens. Environ. 2002, 80, 143-156.

26. Howe, D. Personal Communication, 2006. 
27. Wilson, B. Personal Communication, 2006.

28. Mumby, P.J.; Green, E.P.; Edwards, A.J.; Clark, C.D. The cost-effectiveness of remote sensing for tropical coastal resources assessment and management. J. Environ. Manage. 1999, 55, 157-166.

29. Malthus, T.J.; Mumby, P.J. Remote sensing of the coastal zone: An overview and priorities for future research. Int. J. Remote Sens. 2003, 24, 2805-2815.

30. Phinn, S.R.; Stow, D.A.; Franklin, J.; Mertes, L.A.K.; Michaelsen, J. Remotely sensed data for ecosystem analyses: Combining hierarchy theory and scene models. Environ. Manage. 2003, 31, 429-441.

31. Green, E.P.; Mumby, P.J.; Edwards, A.J.; Clark, C.D. Remote Sensing Handbook for Tropical Coastal Management; UNESCO: Paris, France, 2000.

32. Stehman, S.V. Selecting and interpreting measures of thematic classification accuracy. Remote Sens. Environ. 1997, 62, 77-89.

33. Foody, G.M. Status of land cover classification accuracy assessment. Remote Sens. Environ. 2002, 80, 185-201.

34. Jensen, J.R. Introductory Digital Image Processing: A Remote Sensing Perspective; Prentice Hall: Upper Saddle River, NJ, USA, 2005.

35. Congalton, R.G. A review of assessing the accuracy of classifications of remotely sensed data. Remote Sens. Environ. 1991, 37, 35-46.

36. Pontius, R.G.; Millones, M. Death to Kappa: birth of quantity disagreement and allocation disagreement for accuracy assessment. Int. J. Remote Sens. 2012, 32, 4407-4429.

37. Foody, G.M. Classification accuracy assessment. IEEE Geosci. Remote Sens. Soc. Newsl. 2011, June, 8-14.

38. Wulder, M. Optical remote-sensing techniques for the assessment of forest inventory and biophysical parameters. Progr. Phys. Geogr. 1998, 22, 449-476.

39. de Bruin, S.; Hunter, G.J. Making the trade-off between decision quality and information cost. Photogramm. Eng. Remote Sensing 2003, 69, 91-98.

40. Lewis, D.; Hill, J.; Cowie, I.D. Bullo River Station Flora and Vegetation Survey, Northern Territory: and Reconnaissance Soil-Landscape Investigation; Technical Report No. 02/2010D; Department of Natural Resources, Environment, The Arts and Sport, Northern Territory Government: Palmerston, NT, Australia, 2010.

41. Hnatiuk, K.; Thackway, R.; Walker, J. Vegetation. In Australian Soil and Land Survey: Field Handbook; CSIRO Publishing: Collingwood, VIC, Australia, 2008; p. 111.

42. ESCAVI. Australian Vegetation Attribute Manual: National Vegetation Information System; Version 6.0. Executive Steering Committee for Australian Vegetation Information, Department of the Environment and Heritage: Canberra, Australia, 2003.

43. Lewis, D.; Phinn, S. Accuracy assessment of vegetation community maps generated by aerial photography interpretation: Perspective from the tropical savanna, Australia. J. Appl. Remote Sens. 2011, doi:10.1117/1.3662885.

44. Tickell, S.J.; Rajaratnam, L.R. Water Resources Survey of the Western Victoria River District, Bullo River Station; Power and Water Authority, Water Resources Division, Northern Territory Government: Darwin, NT, Australia, 1995. 
45. Curran, P.J. Classification. In Principles of Remote Sensing; Longman: London, UK, 1985; pp. 209-216.

46. Green, E; Clark, C; Mumby, P; Edwards, A; Ellis, A. Remote sensing techniques for mangrove mapping. Int. J. Remote Sens. 1998, 5, 935-956.

47. Lillesand, T; Kiefer, R. Remote Sensing and Image Interpretation; John Wiley and Sons Inc.: New York, NY, USA, 1994.

48. Mather, P. Computer Processing of Remotely Sensed Images: An Introduction; John Wiley and Sons Ltd.: West Sussex, UK, 1999.

49. Lewis, D.; Phinn, S.; Pfitzner, K. Pixel-based image classification to map vegetation communities using SPOT5 and Landsat5 Thematic Mapper data in a tropical savanna, northern Australia. Can. J. Remote Sens. 2012, accepted.

50. Lewis, D.; Phinn, S.; Arroyo, L. Object-based image analysis to map vegetation communities using SPOT5, Landsat5 TM, field and ancillary data in a tropical savanna, northern Australia. Int. J. Remote Sens. 2012, accepted.

51. Salehi, B.; Zhang, Y.; Zhong, M.; Vivek, D. Object-based classification of urban areas using VHR imagery and height points ancillary data. Remote Sens. 2012, 4, 2256-2276.

52. Bahadur, K. Improving Landsat and IRS image classification: evaluation of unsupervised and supervised classification through band ratios and DEM in a mountainous landscape in Nepal. Remote Sens. 2009, 1, 1257-1272.

53. Polychronaki, A.; Gitas, I.Z. Burned area mapping in Greece using SPOT4-HRVIR images and object-based image analysis. Remote Sens. 2012, 4, 424-438.

54. Whiteside, T.G.; Boggs, G.S.; Maier, S.W. Comparing object-based and pixel-based classifications for mapping savannas. Int. J. Appl. Earth Obs. Geoinf. 2011, 13, 884-893.

55. Duro, D.C.; Franklin, S.E.; Dube, M.G. A comparison of pixel-based and object-based image analysis with selected machine learning algorithms for the classification of agricultural landscapes using SPOT5 HRG imagery. Remote Sens. Environ. 2012, 118, 259-272.

56. Yan, G.; Mas, J.F.; Maathuis, B.H.P.; Xiangmin, Z.; Dijk, P.M.V. Comparison of pixel-based and object-oriented image classification approaches - A case study in a coal fire area, Wuda, Inner Mongolia, China. Int. J. Remote Sens. 2006, 27, 4039-4055.

57. Harvey, K.R.; Hill, G.J.E. Vegetation mapping of a tropical freshwater swamp in the Northern Territory, Australia: A comparison of aerial photography, Landsat TM and SPOT satellite imagery. Int. J. Remote Sens. 2001, 22, 2911-2925.

58. Dingle Robertson, L.; King, D.J. Comparison of pixel- and object-based classification in land cover change mapping. Int. J. Remote Sens. 2011, 32, 1505-1529.

59. Benson, J. Sampling, strategies and costs of regional vegetation mapping. The Globe, Journal of the Australian Map Circle. 1995, 43, 18-27.

60. Neldner, J.V. Vegetation Survey and Mapping in Queensland: Its Relevance and Future, and the Contribution of the Queensland Herbarium; Queensland Botany Bulletin No. 12; Queensland Herbarium, Department of Environment and Heritage: Brisbane, QLD, Australia, 1994. 


\section{Appendix}

Appendix 1. Twenty-two vegetation community descriptions assessed across the study area at the National Vegetation Information System (NVIS) sub-association level.

\begin{tabular}{|c|c|}
\hline $\begin{array}{l}\text { Vegetation } \\
\text { Community } \\
\text { ID }\end{array}$ & $\begin{array}{c}\text { Vegetation Community Description } \\
\text { NVIS Sub-Association }\end{array}$ \\
\hline 1 & $\begin{array}{l}\text { Eucalyptus tectifica } \pm \text { Corymbia foelscheana, Erythrophleum chlorostachys, Corymbia grandifolia Low } \\
\text { Woodland over Cochlospermum fraseri, Terminalia canescens, Brachychiton tuberculatus Tall Sparse } \\
\text { Shrubland over Eriachne obtusa, Heteropogon contortus, Sehima nervosum, Ampelocissus frutescens, } \\
\text { Waltheria indica Mid Tussock Grassland }\end{array}$ \\
\hline 2 & $\begin{array}{l}\text { Corymbia dichromophloia } \pm \text { Erythrophleum chlorostachys, Terminalia latipes Low Open Woodland over } \\
\text { Cochlospermum fraseri } \pm \text { Croton arnhemicus, Terminalia canescens, Corymbia dichromophloia Tall } \\
\text { Sparse Shrubland over Triodia bitextura, Eriachne ciliata, Eriachne obtusa, Stackhousia intermedia, } \\
\text { Phyllanthus exilis Mid Open Hummock Grassland }\end{array}$ \\
\hline 3 & $\begin{array}{l}\text { Corymbia bella } \pm \text { Gyrocarpus americanus, Adansonia gregorii, Corymbia polycarpa Mid Woodland over } \\
\text { Bauhina cunninghamii, Acacia holosericea, Ficus aculeata, Flueggea virosa Low Open Woodland over } \\
\text { Heteropogon contortus, Mnesithea rottboelioides, Hyptis suaveolens, Grewia retusifolia, Sida acuta Very } \\
\text { Tall Tussock Grassland }\end{array}$ \\
\hline 4 & $\begin{array}{l}\text { Lophostemon grandiflorus } \pm \text { Adansonia gregorii, Celtis philippensis Mid Woodland over Buchanania } \\
\text { obovata, Bauhinia cunninghamii, Pouteria sericea, Calytrix brownii, Lophostemon grandiflorus Tall Sparse } \\
\text { Shrubland over Mnesithea rottboelioides, Heteropogon contortus, Ischaemum australe, Triodia bynoei, } \\
\text { Cajanus latisepalus Mid Open Tussock Grassland }\end{array}$ \\
\hline 5 & $\begin{array}{l}\text { Eucalyptus pruinosa } \pm \text { Brachychiton diversifolius, Corymbia confertiflora Low Open Woodland over } \\
\text { Acacia holosericea, Brachychiton tuberculatus, Petalostigma pubescens, Ampelocissus frutescens, } \\
\text { Cochlospermum fraseri Tall Sparse Shrubland over Heteropogon contortus, Grewia retusifolia, Eriachne } \\
\text { obtusa, Themeda triandra, Sehima nervosum, Waltheria indica Mid Tussock Grassland }\end{array}$ \\
\hline 6 & $\begin{array}{l}\text { Eucalyptus miniata } \pm \text { Erythrophleum chlorostachys, Corymbia bleeseri, Terminalia latipes, Corymbia } \\
\text { dichromophloia Mid Open Woodland over Buchanania obovata, Persoonia falcata, Terminalia latipes Tall } \\
\text { Sparse Shrubland over Triodia bitextura, Eriachne ciliata, Cartonema spicatum, Crotalaria medicaginea, } \\
\text { Bulbostylis barbata Mid Open Hummock Grassland }\end{array}$ \\
\hline 7 & $\begin{array}{l}\text { Corymbia grandifolia } \pm \text { Corymbia foelscheana, Corymbia polycarpa, Melaleuca viridiflora Mid Open } \\
\text { Woodland over Cochlospermum fraseri, Brachychiton tuberculatus, Bauhinia cunninghamii, Terminalia } \\
\text { latipes, Grevillea decurrens Tall Sparse Shrubland over Aristida hygrometrica, Eriachne obtusa, Triodia } \\
\text { bitextura, Schizachyrium fragile, Oldenlandia mitrasacmoides Mid Open Tussock Grassland }\end{array}$ \\
\hline 8 & $\begin{array}{l}\text { Dichanthium fecundum, Ludwigia perennis, Melochia corchorifolia, Nelsonia campestris, Eleocharis } \\
\text { acutangula Mid Tussock Grassland with upper strata } \pm \text { Acacia farnesiana, Bauhinia cunninghamii, } \\
\text { Melaleuca viridiflora, Melaleuca nervosa Low Open Woodland }\end{array}$ \\
\hline 10 & $\begin{array}{l}\text { Eucalyptus phoenicea } \pm \text { Corymbia dichromophloia, Erythrophleum chlorostachys, Corymbia ferruginea, } \\
\text { Terminalia latipes Low Open Woodland over Calytrix exstipulata, Cochlospermum fraseri, Terminalia } \\
\text { latipes, Croton arnhemicus Tall Sparse Shrubland over Triodia bitextura, Eriachne ciliata, Petalostigma } \\
\text { quadriloculare, Stackhousia intermedia, Oldenlandia mitrasacmoides Mid Open Tussock Grassland }\end{array}$ \\
\hline 11 & $\begin{array}{l}\text { Corymbia polycarpa } \pm \text { Grevillea pteridifolia, Gyrocarpus americanus Mid Open Woodland over Melaleuca } \\
\text { viridiflora, Acacia difficilis, Melaleuca nervosa Medium Low Open Woodland over Chrysopogon setifolius, } \\
\text { Eriachne obtusa, Sorghum stipoideum, Alloteropsis semialata, Murdannia graminea Mid Tussock Grassland }\end{array}$ \\
\hline
\end{tabular}


Appendix 1. Cont.

12 Buchanania obovata, Terminalia latipes \pm Corymbia polysciada, Owenia vernicosa, Xanthostemon paradoxus Low Open Woodland over Buchanania obovata, Cochlospermum fraseri, Croton arnhemicus Mid Sparse Shrubland over Triodia bitextura, Eriachne ciliata, Sorghum bulbosum, Bulbostylis barbata, Corchorus sidioides Mid Open Hummock Grassland

13 Corymbia ptychocarpa \pm Melaleuca leucadendra, Pandanus spiralis, Banksia dentata Mid Woodland over Pandanus spiralis, Acacia pellita, Acacia difficilis, Corymbia ptychocarpa Low Open Palmland over Mnesithea rottboelioides, Pandanus spiralis, Fimbristylis pauciflora, Scleria rugosa, Acacia pellita Mid Tussock Grassland

Eucalyptus brevifolia \pm Corymbia dichromophloia, Eucalyptus phoenicea, Erythrophleum chlorostachys Low Open Woodland over Calytrix achaeta, Cochlospermum fraseri, Wrightia saligna, Grevillea prasina, Acacia lycopodifolia Mid Sparse Shrubland over Triodia bitextura, Eriachne ciliata, Eriachne mucronata, Acacia translucens, Grevillea dryandri Low Open Hummock Grassland

Melaleuca sericea \pm Cochlospermum fraseri, Erythrophleum chlorostachys, Melaleuca minutifolia Low Open Woodland over \pm Calytrix exstipulata, Cochlospermum fraseri Mid Sparse Shrubland Triodia bitextura, Eriachne mucronata, Petalostigma quadriloculare, Eriachne ciliata, Fimbristylis pterygosperma Low Open Hummock Grassland Corymbia ferruginea \pm Erythrophleum chlorostachys, Eucalyptus phoenicea Low Open Woodland over Cochlospermum fraseri, Grevillea agrifolia, Psydrax pendulina, Brachychiton fitzgeraldianus Tall Sparse Shrubland over Triodia bitextura, Eriachne ciliata, Eriachne obtusa, Ampelocissus frutescens, Haemodorum ensifolium Mid Open Hummock Grassland Corymbia foelscheana \pm Corymbia confertiflora, Corymbia grandifolia, Brachychiton diversifolius, Bauhinia cunninghamii Mid Woodland over Petalostigma pubescens, Brachychiton tuberculatus, Planchonia careya, Hakea arborescens, Corymbia foelscheana Tall Sparse Shrubland over Heteropogon contortus, Sehima nervosum, Sorghum plumosum, Themeda triandra, Grewia retusifolia Mid Tussock Grassland Melaleuca minutifolia \pm Terminalia platyphylla, Cochlospermum fraseri Low Woodland over Flueggea virosa, Hakea arborescens, Terminalia canescens, Cochlospermum fraseri Mid Sparse Shrubland over Panicum mindanaense, Themeda triandra, Grewia retusifolia, Bacopa floribunda, Ampelocissus frustescens Mid Tussock Grassland Melaleuca viridiflora \pm Petalostigma pubescens, Acacia difficilis, Corymbia polycarpa Low Woodland over Acacia difficilis, Verticordia cunninghamii, Melaleuca viridiflora, Cochlospermum fraseri Tall Sparse Shrubland over Chrysopogon setifolius, Eriachne obtusa, Sorghum stipoideum, Scleria rugosa, Melaleuca viridiflora Mid Tussock Grassland

Melaleuca leucadendra \pm Terminalia platyphylla, Ficus coronulata, Nauclea orientalis Mid Woodland over Barringtonia acutangula, Acacia holosericea, Syzygium eucalyptoides subsp. eucalyptoides, Acacia pellita, Bauhinia cunninghamii Low Open Woodland over Mnesithea rottboelioides, Chrysopogon oliganthus, Cyperus conicus, Nelsonia campestris, Eriachne festucacea Mid Open Tussock Grassland Mix of Acacia spp., Grevillea spp., Gardenia spp., Terminalia latipes, Buchanania obovata Tall Sparse Shrubland over Triodia bitextura, Triodia bynoei, Eriachne ciliata, Schizachyrium fragile, Bulbostylis barbata Mid Open Hummock Grassland Xanthostemon paradoxus, Pouteria sericea, Acacia lamprocarpa, Ziziphus quadrilocularis, Alstonia spectabilis Mid Woodland over Grewia breviflora, Ziziphus quadrilocularis, Buchanania obovata, Celtis philippensis, Pouteria sericea Low Woodland over Pseudochaetochloa australiensis, Cyperus microsephalus, Jasminum didymum, Cayratia trifolia, Hypoestes floribunda Mid Sparse Tussock Grassland Eleocharis sphacelata, Oryza australiensis \pm Pseudoraphis spinescens, Whiteochloa cymbiformis, Eleocharis acutangula Low Closed Sedgeland 
Appendix 2. Output vegetation community maps for the seven mapping approaches, three image dataset and at the 1:25,000 and 1:100,000 spatial scales. API: 1:50,000 aerial photography mosaic at 1:25,000 and 1:100,000. Datum: GDA94, Coordinate System: Decimal Degrees 129.578-15.877, 129.825-15.597, 129.469-15.534, 129.688-15.7.

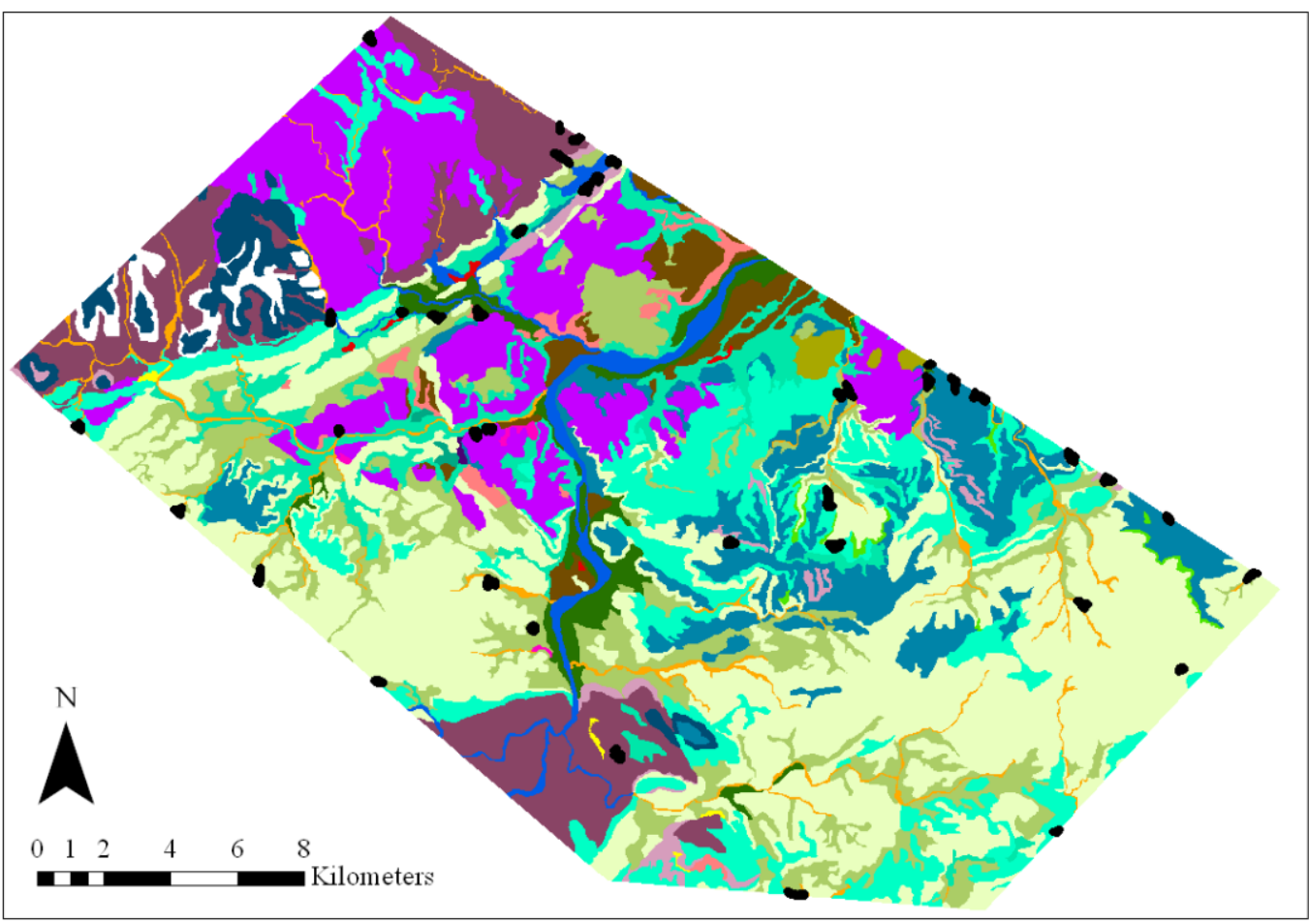

Legend

Végetaion Commurity Community 1 Community 2 Commurity 3 Community 4 Commurity 5 Commurity 6 Commmity 7 Community 8 Commurity 10 Community 11 Commrity 12 Community 13 Community 15

Commurity 16 Community 17 Community 18 Community 19 Commurity 20 Community 21 Community 22 Commurity 28 Commrity 30

The black dots indicate the polygons removed to produce the 1:100,000 map.

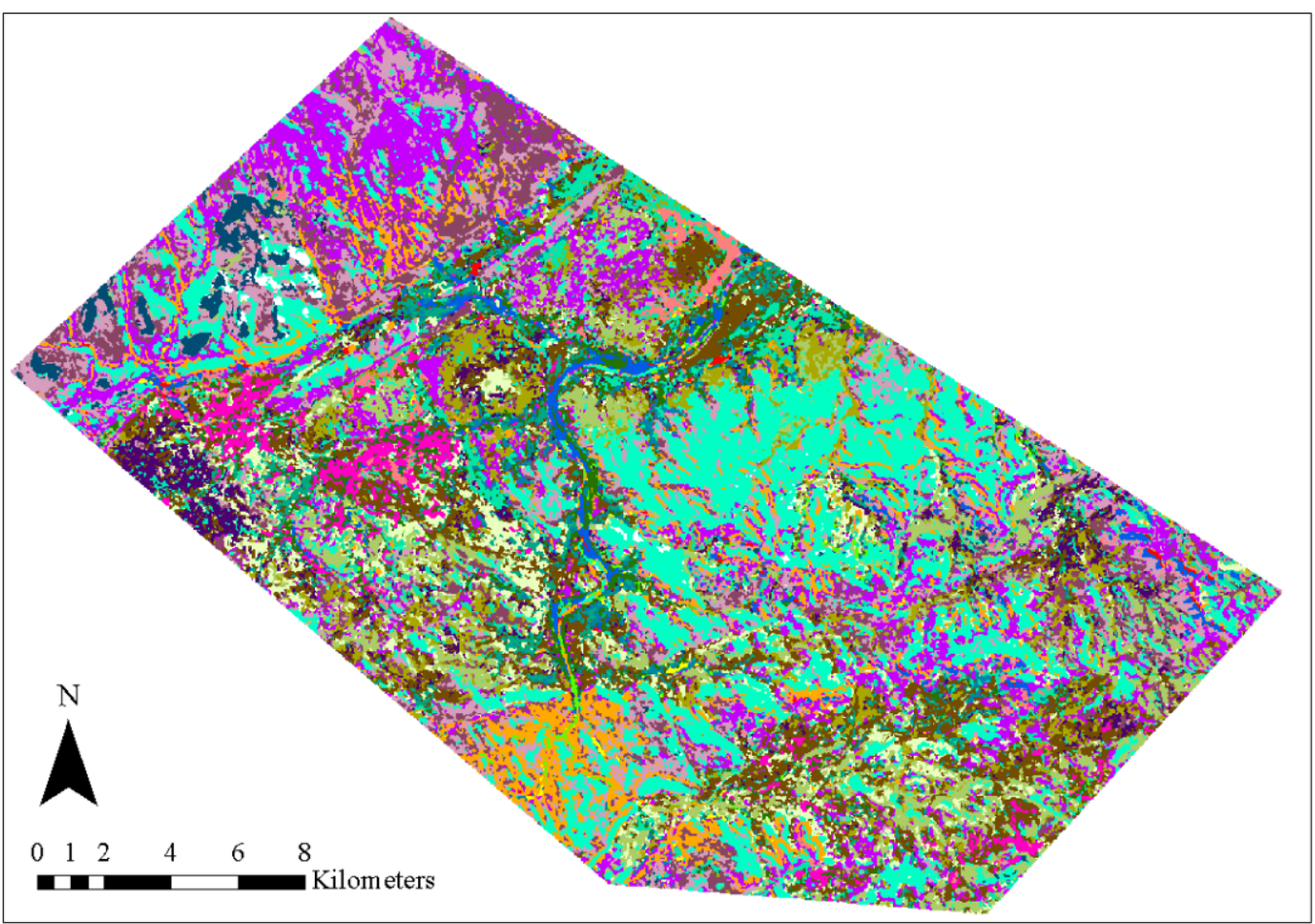

Legand

Vegetaion Commurity Commarity 1

Community 2

Commority 3 Commerity 4 Community 5 Commurity 6 Community 7 Community 8 Commrity 10 Community 11 Community 12 Community 13 Community 15 Commurity 16 Commurity 17 Commanity 18 Communty 19 Commurity 20 Commurity 21 Communty 22 Community 28 Commrity 30

PBIA image-only: Landsat5 TM at 1:25,000. 
Appendix 2. Cont.
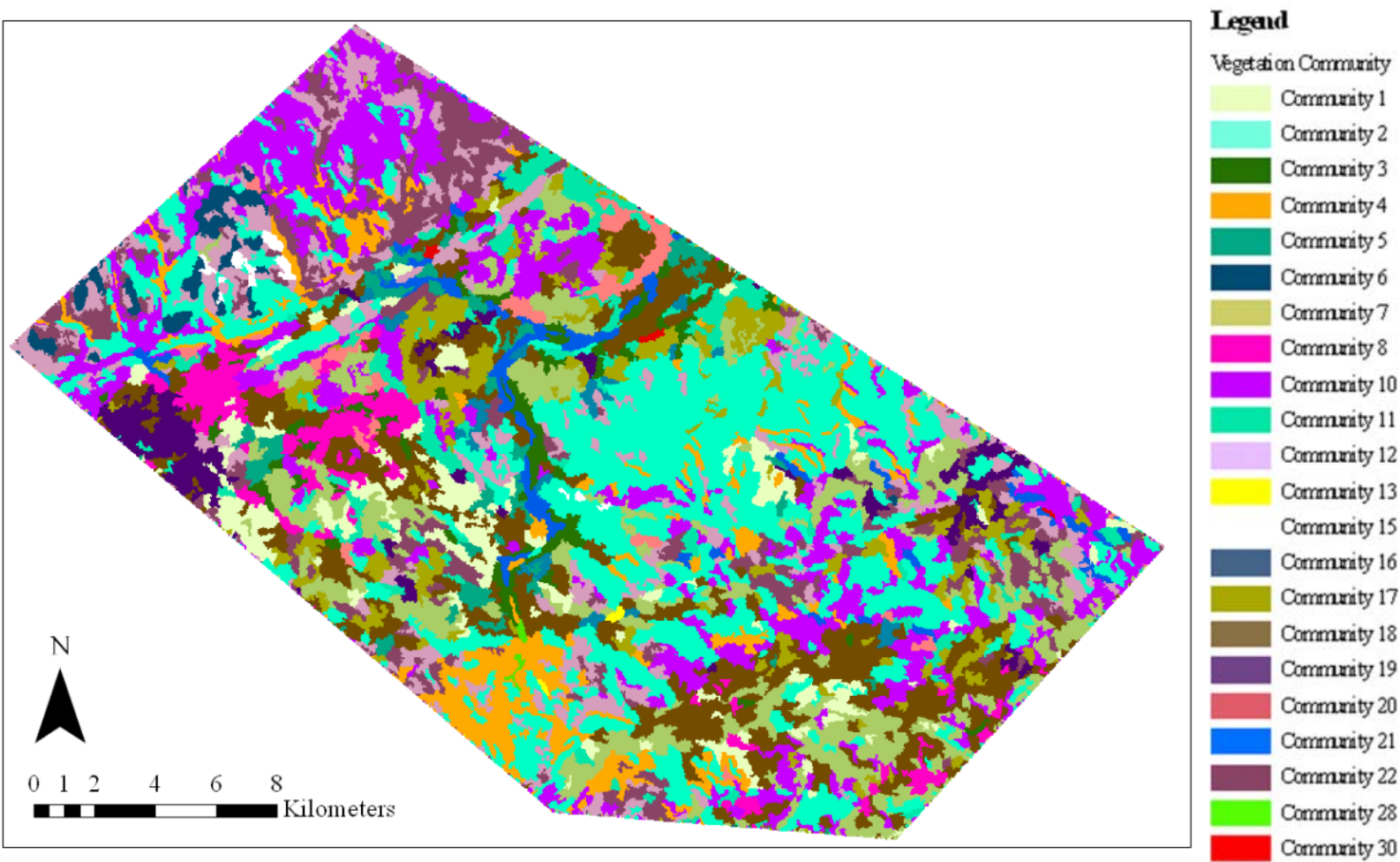

PBIA image-only: Landsat5 TM at 1:100,000.
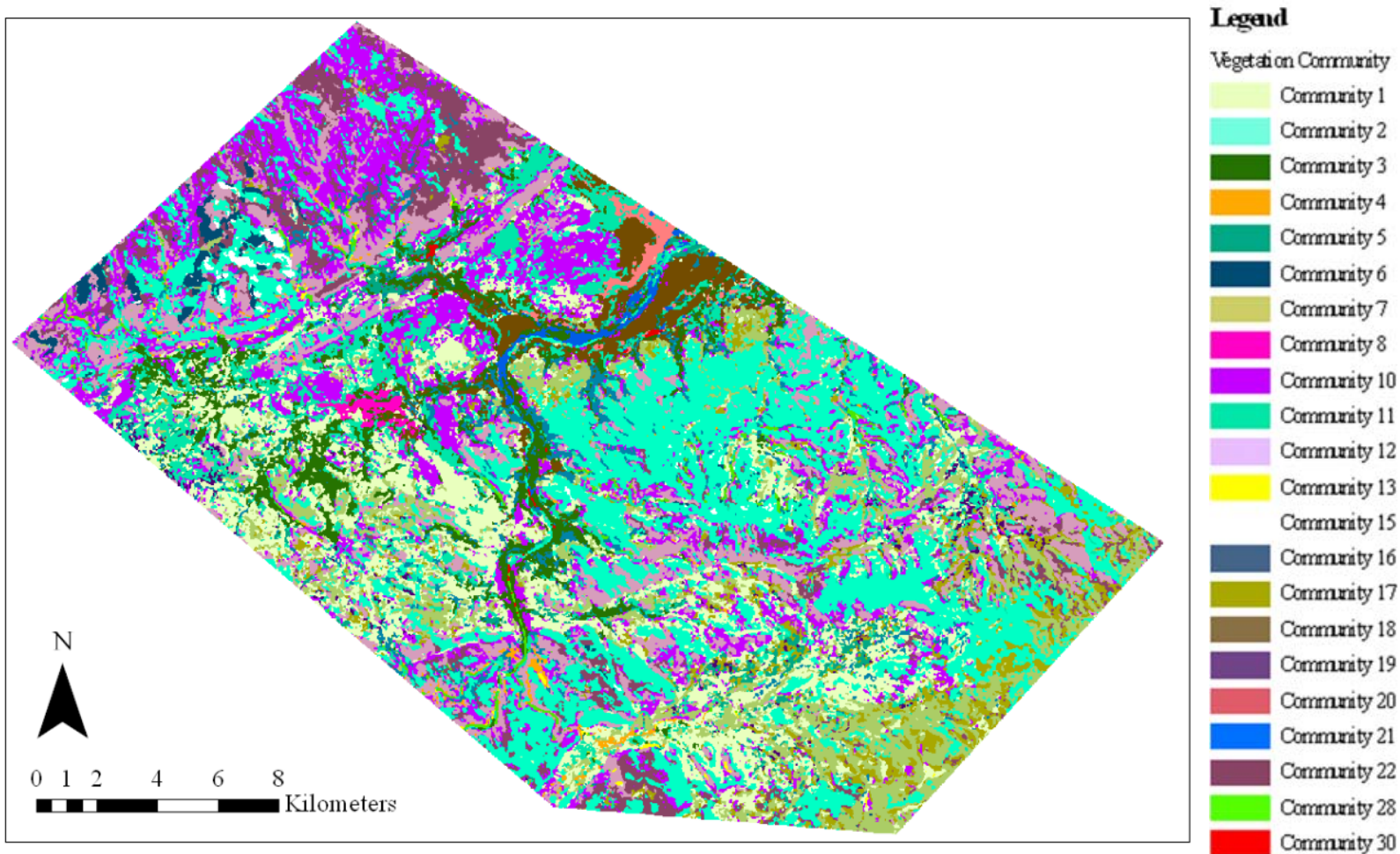

PBIA integrated: Landsat5 TM (DEM and slope) at 1:25,000. 
Appendix 2. Cont.

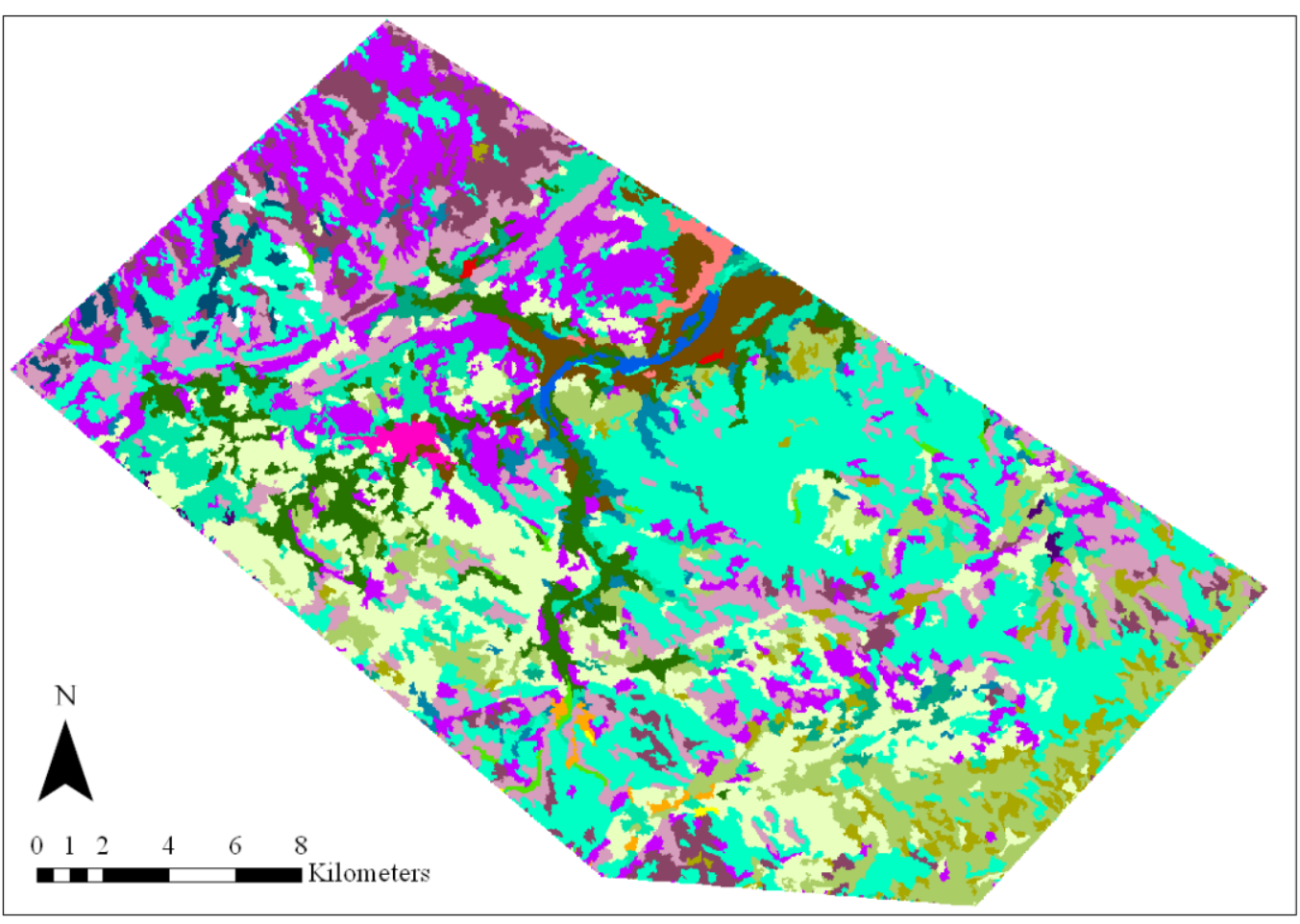

Legend

Vegetaion Cormurnity Commurity 1

Commurity 2

Commurity 3

Commurity 4

Community 5

Commurity 6

Commurity 7

Commurity 8

Commurity 10

Commurity 11

Commurity 12

Commurity 13

Commurity 15

Commurity 16

Commurity 17

Commurity 18

Commurity 19

Community 20

Commurity 21

Community 22

Commurity 28

Commurity 30

PBIA integrated: Landsat5 TM (DEM and slope) at 1:100,000.

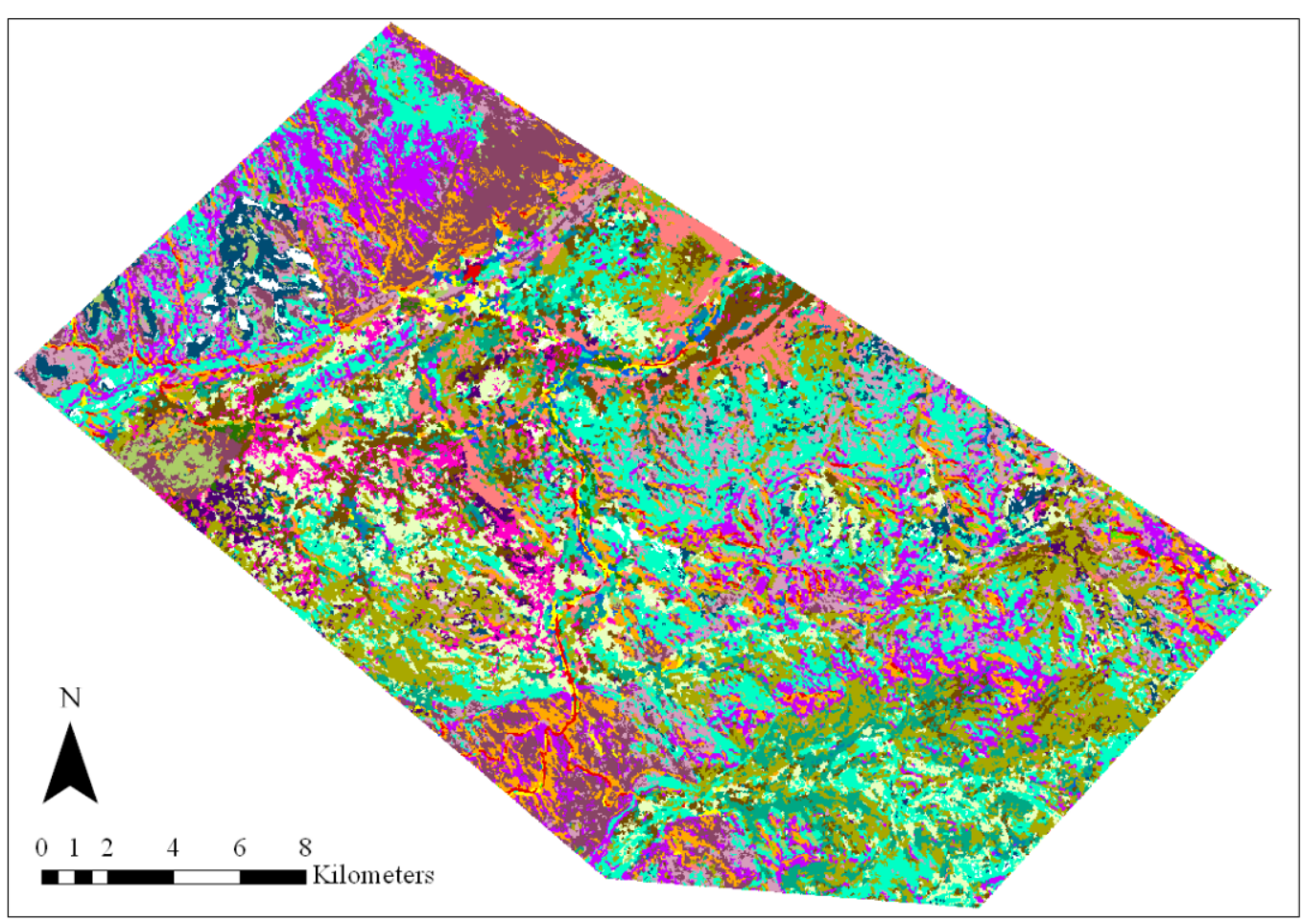

\section{Legend}

Végetaion Commurity Commurity 1 Commurity 2 Commurity 3 Commrity 4 Commurity 5 Commurity 6 Commurity 7 Commurity 8 Commarity 10 Community 11 Community 12 Commrity 13 Commurity 15 Community 16 Community 17 Community 18 Communty 19 Commurity 20 Commurity 21 Commurity 22 Community 28 Commurity 30

PBIA image-only: SPOT5 at 1:25,000. 
Appendix 2. Cont.

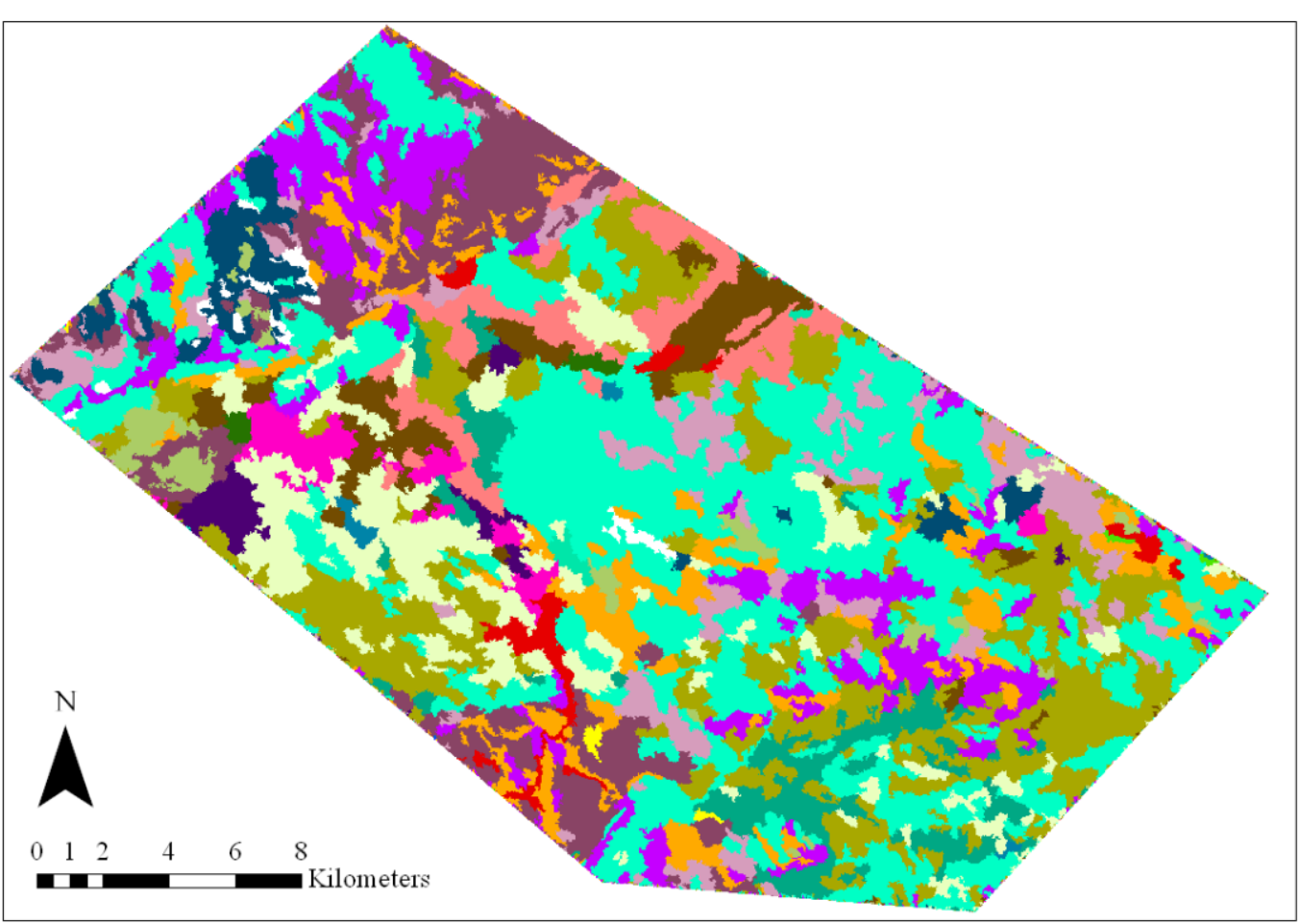

Legend

Vegetaion Cormurnity Community 1

Commrity 2

Commrity 3

Commrity 4

Community 5

Commurity 6

Commurity 7

Commurity 8

Commurity 10

Commurity 11

Commurity 12

Commurity 13

Community 15

Commurity 16

Commurity 17

Commurity 18

Commurity 19

Community 20

Commurity 21

Commurity 22

Commurity 28

PBIA image-only: SPOT5 at 1:100,000.

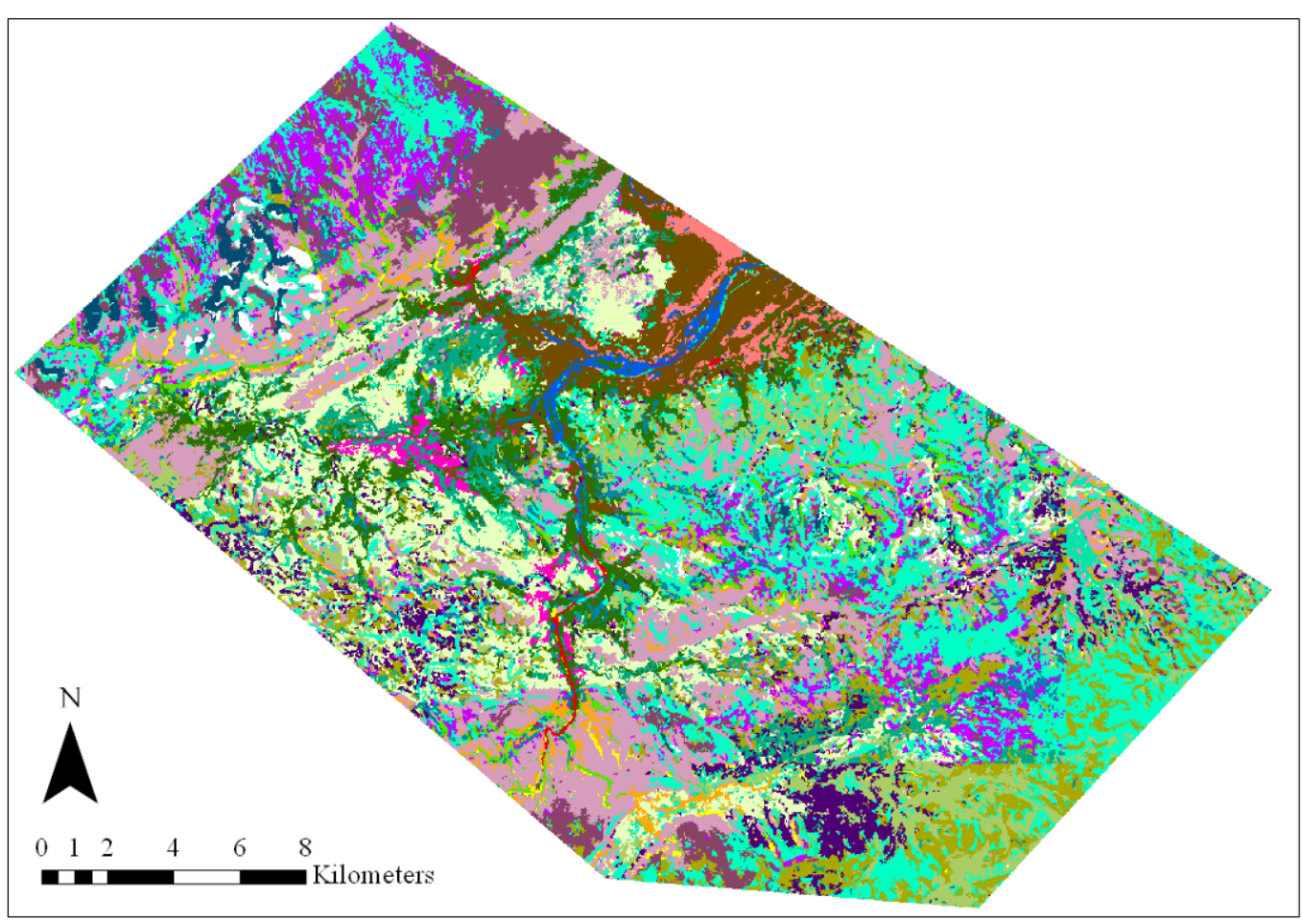

\section{Legend}

Végetaion Commurity Commurity 1 Commurity 2 Commurity 3 Commurity 4 Commurity 5 Commurity 6 Commurity 7 Community 8 Community 10 Community 11 Community 12 Commrity 13 Community 15 Community 16 Commurity 17 Community 18 Commurity 19 Community 20 Commurity 21 Commrity 22 Community 28 Commurity 30

PBIA integrated: SPOT5 at 1:25,000. 
Appendix 2. Cont.

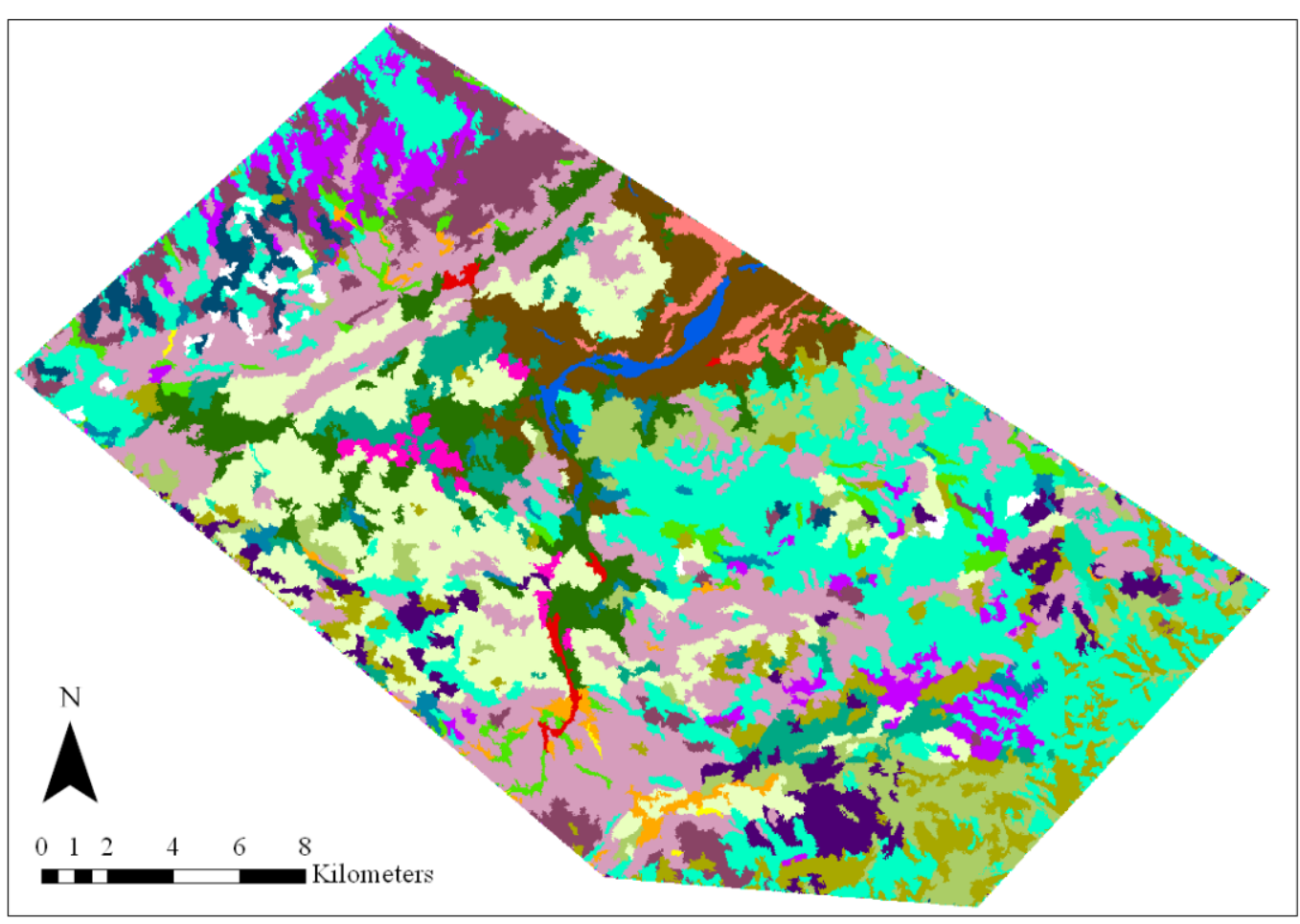

Legend

Vegetaion Cormurnity Community 1

Commurity 2

Commrity 3

Commrity 4

Community 5

Commurity 6

Commurity 7

Commurity 8

Commurity 10

Commurity 11

Commurity 12

Commurity 13

Community 15

Commrity 16

Commurity 17

Commurity 18

Commurity 19

Commurity 20

Commurity 21

Commurity 22

Commmity 28

PBIA integrated: SPOT5 at 1:100,000.

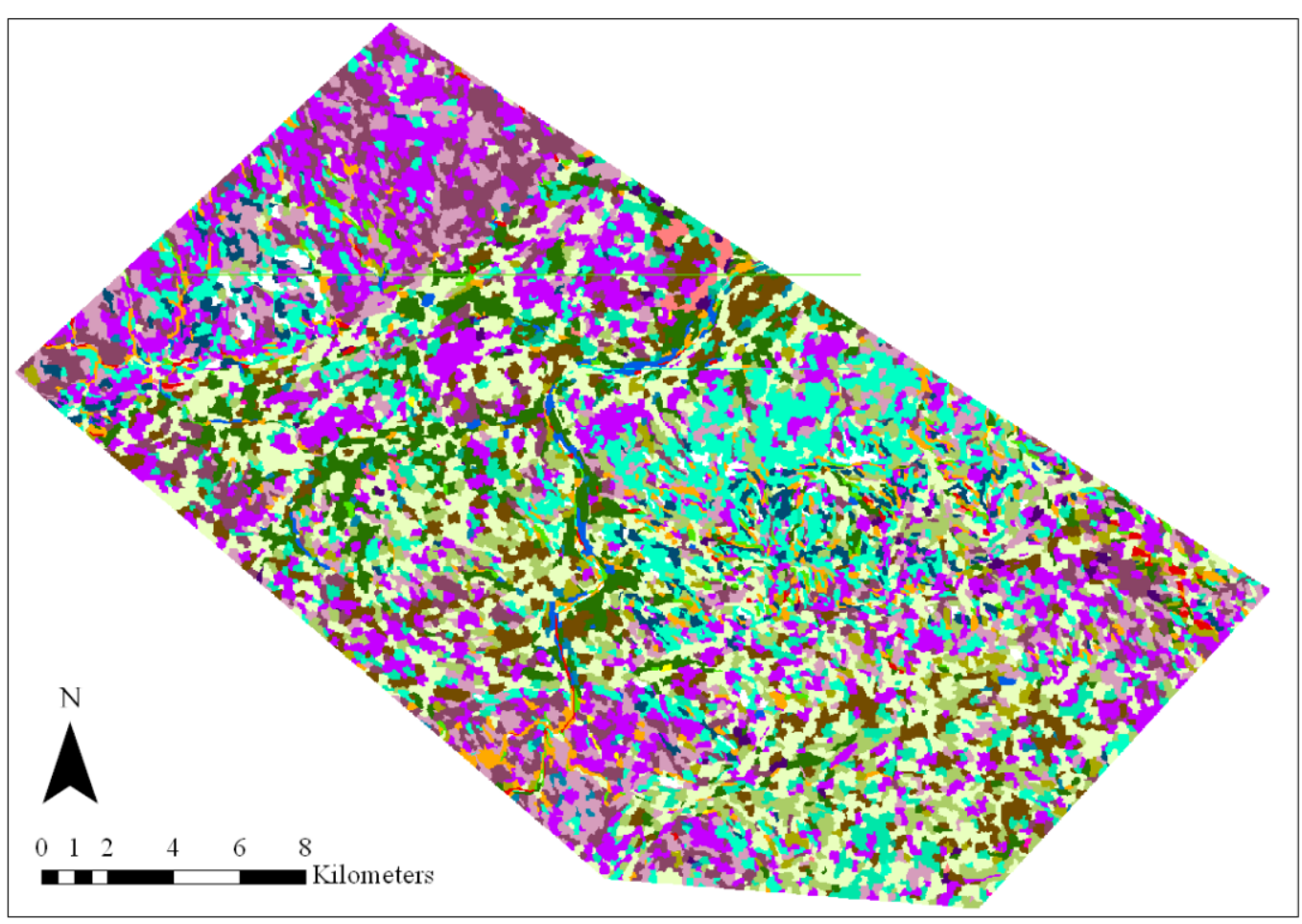

Legend

Végetaion Cormurity Commurity 1 Commurity 2

Commurity 3

Commrity 4

Cormmurity 5

Commurity 6

Community 7

Commurity 8

Community 10 Commurity 11

Community 12

Commrity 13

Community 15

Community 16

Community 17

Communty 18

Commurity 19

Community 20

Commurity 21

Community 22

Communty 28

Commurity 30

GEOBIA NN image-only: Landsat5 TM at 1:25,000. 
Appendix 2. Cont.

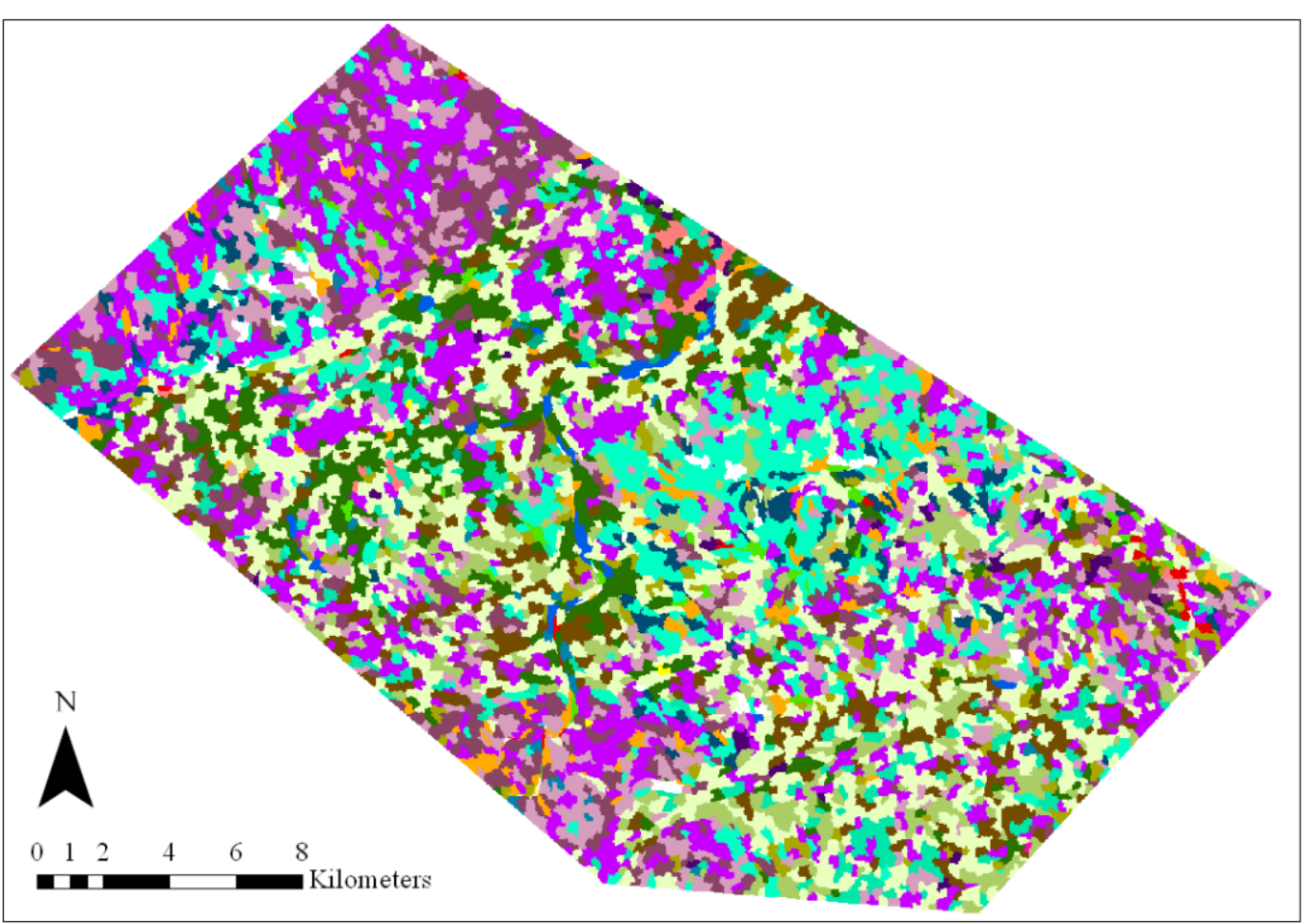

Legend

Vegetaion Cormurnity Community 1

Commurity 2

Commrity 3

Commrity 4

Community 5

Commurity 6

Commurity 7

Commurity 8

Commrity 10

Commurity 11

Commurity 12

Commurity 13

Community 15

Commrity 16

Commurity 17

Commurity 18

Commurity 19

Commurity 20

Commurity 21

Commurity 22

Commmity 28

GEOBIA NN image-only: Landsat5 TM at 1:100,000.

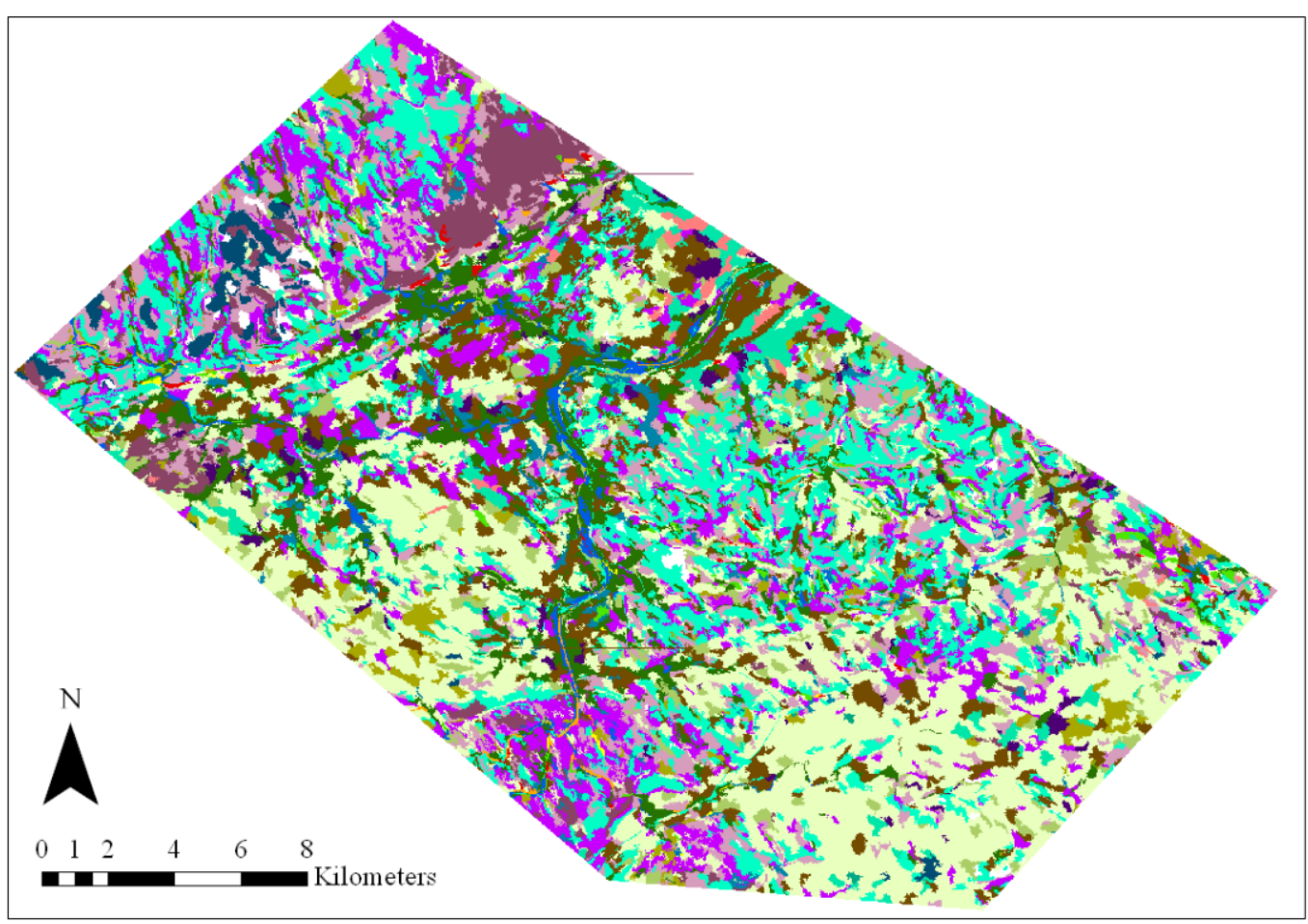

\section{Legend}

Vegettion Cormurity Commurity 1 Commurity 2

Commrity 3

Commrity 4

Commrity 5

Commurity 6

Commurity 7

Commurity 8

Community 10

Commmity 11

Community 12

Commurity 13 Community 15 Community 16 Commurity 17 Commurity 18 Communty 19 Commurity 20 Commurity 21 Commurity 22 Community 28 Commurity 30

GEOBIA NN image-only: SPOT5 at 1:25,000. 
Appendix 2. Cont.
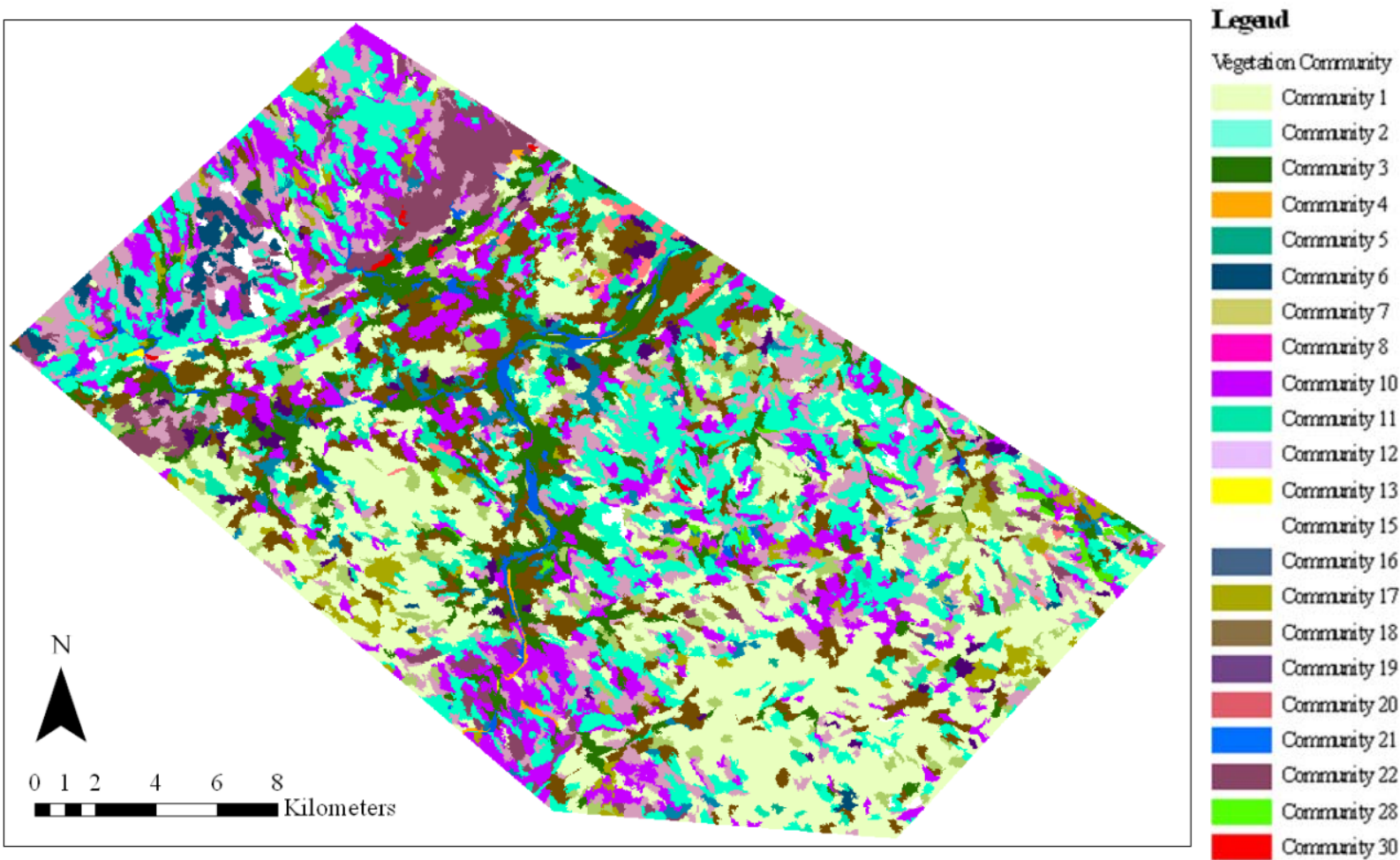

GEOBIA NN image-only: SPOT5 at 1:100,000.
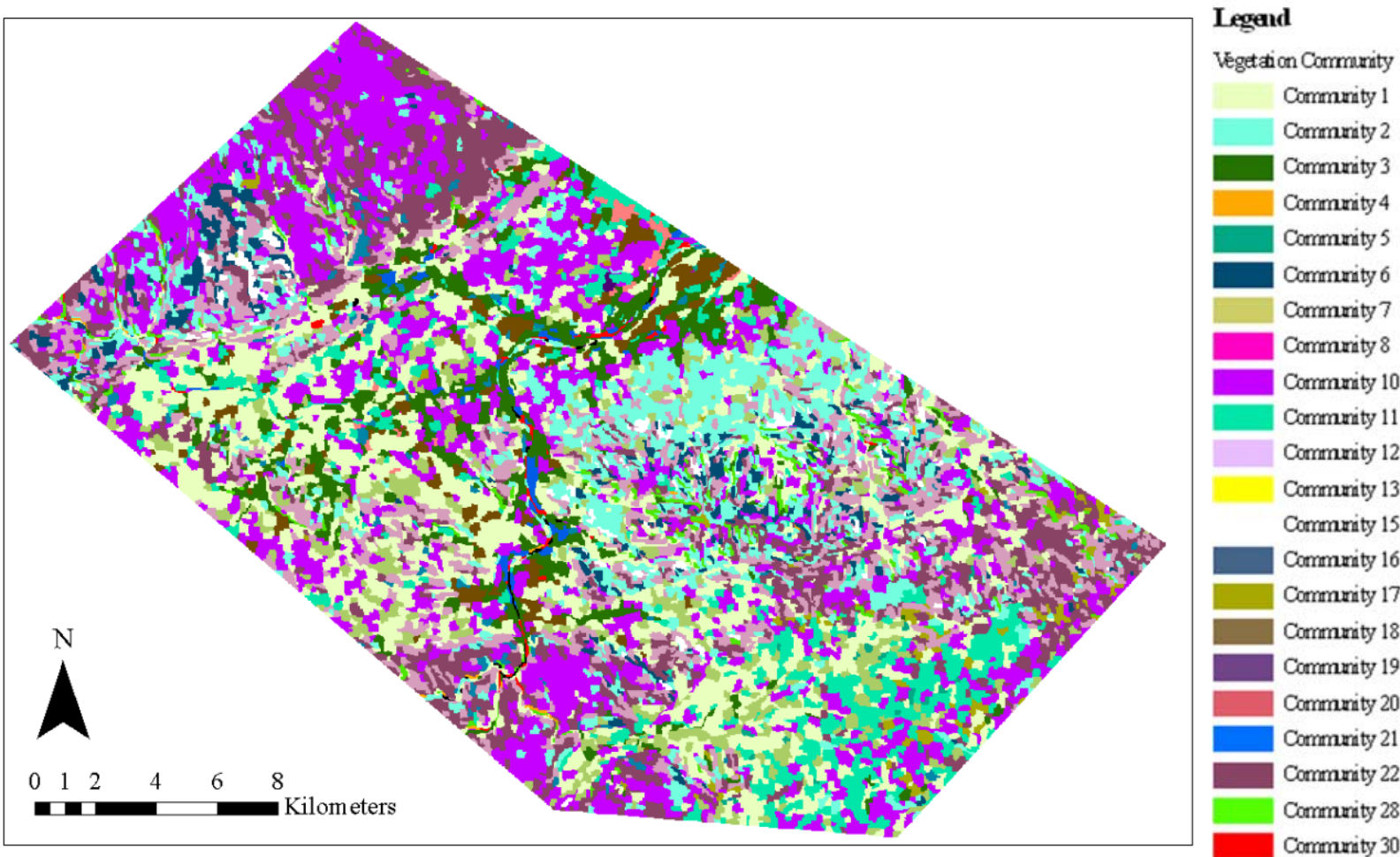

GEOBIA NN integrated: Landsat5 TM (DEM and slope) at 1:25,000. 
Appendix 2. Cont.
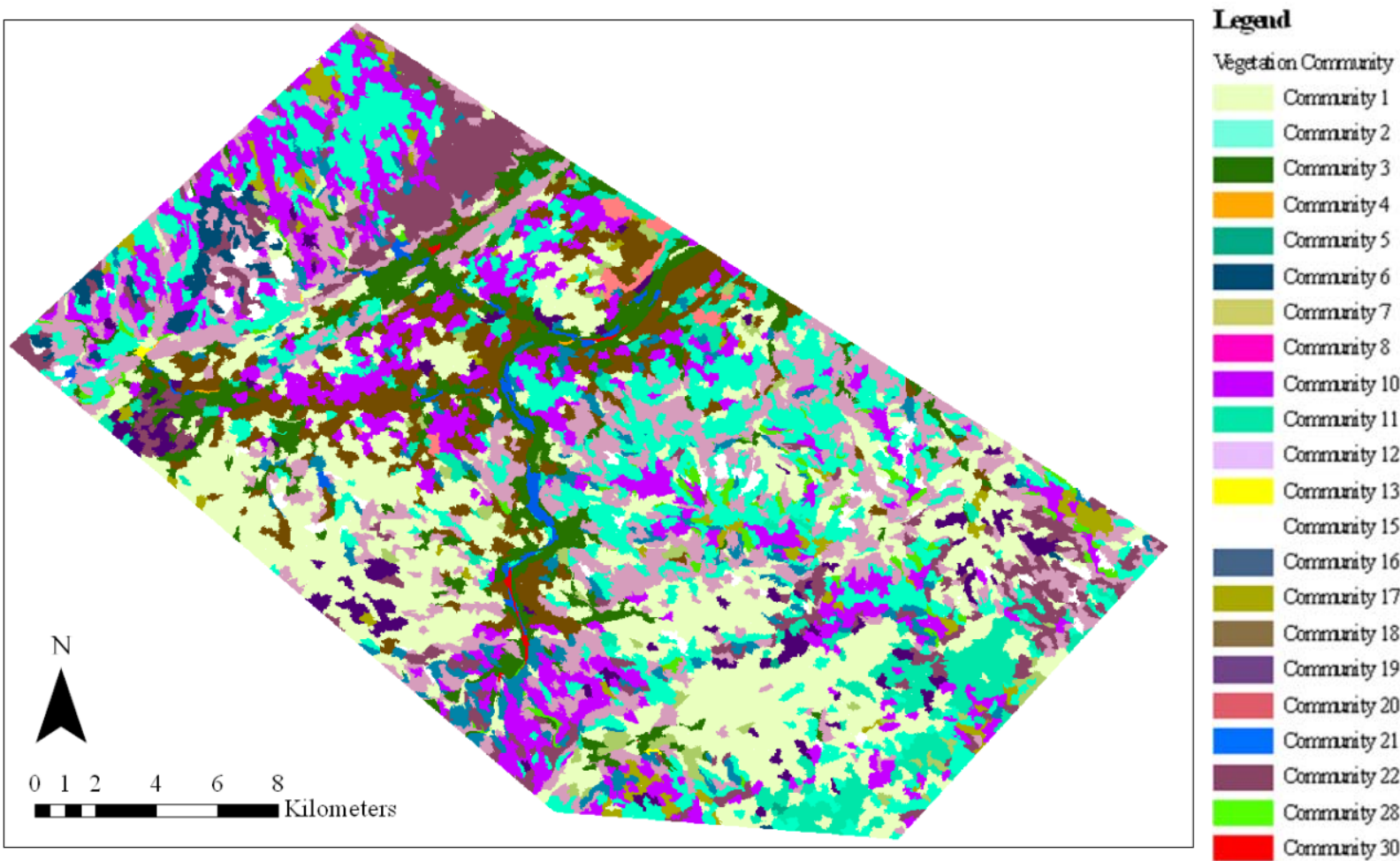

GEOBIA NN integrated: Landsat5 TM (DEM and slope) at 1:100,000.

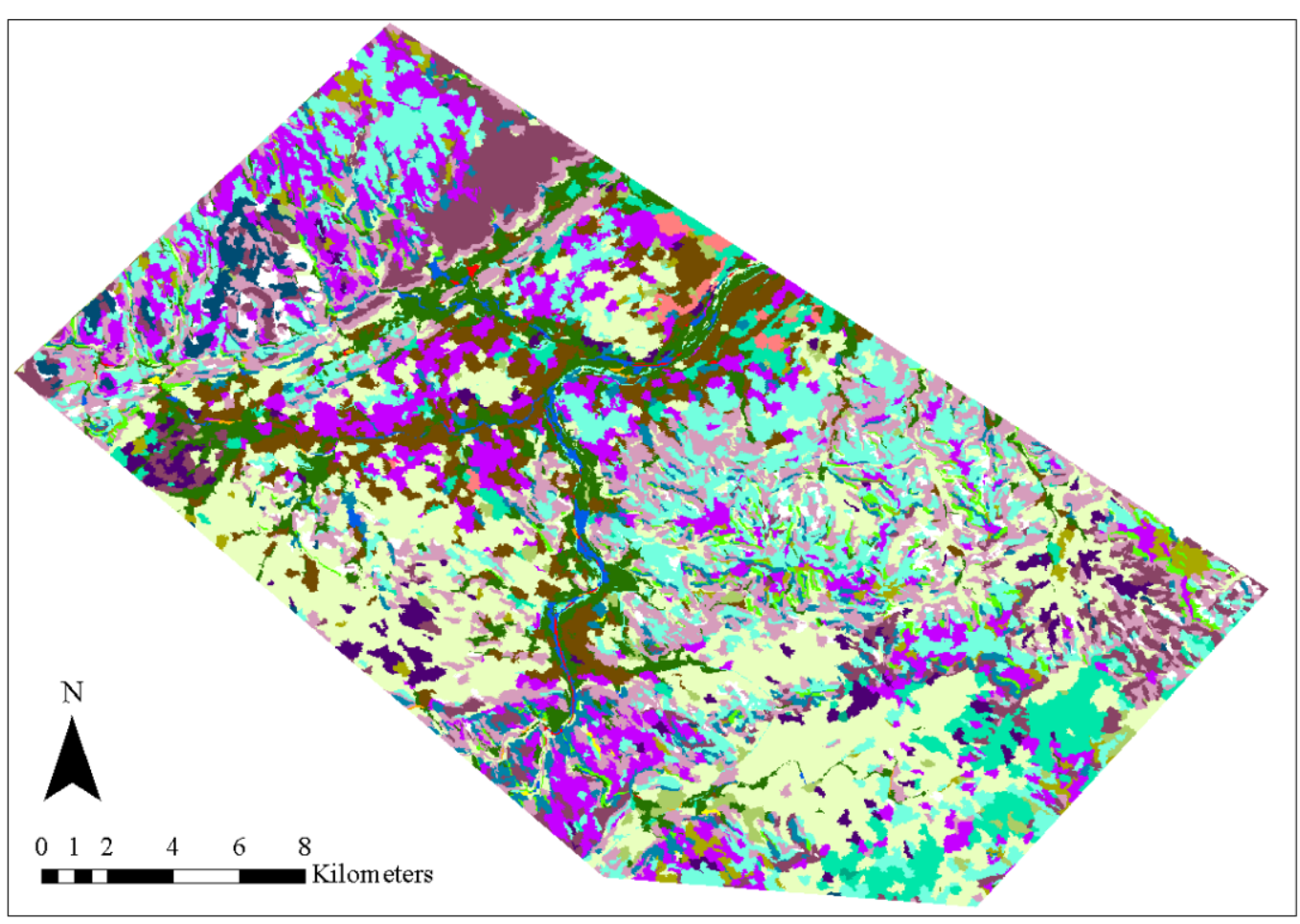

Legend

Vegetion Commurity Commurity 1 Commurity 2

Commurity 3

Commrity 4

Commurity 5

Community 6

Community 7

Commurity 8

Communty 10 Community 11 Community 12 Commurity 13 Commurity 15 Community 16 Commurity 17 Communty 18 Commurity 19 Community 20 Commurity 21 Community 22 Community 28 Commurity 30

GEOBIA NN integrated: SPOT5 (DEM and slope) at 1:25,000. 
Appendix 2. Cont.
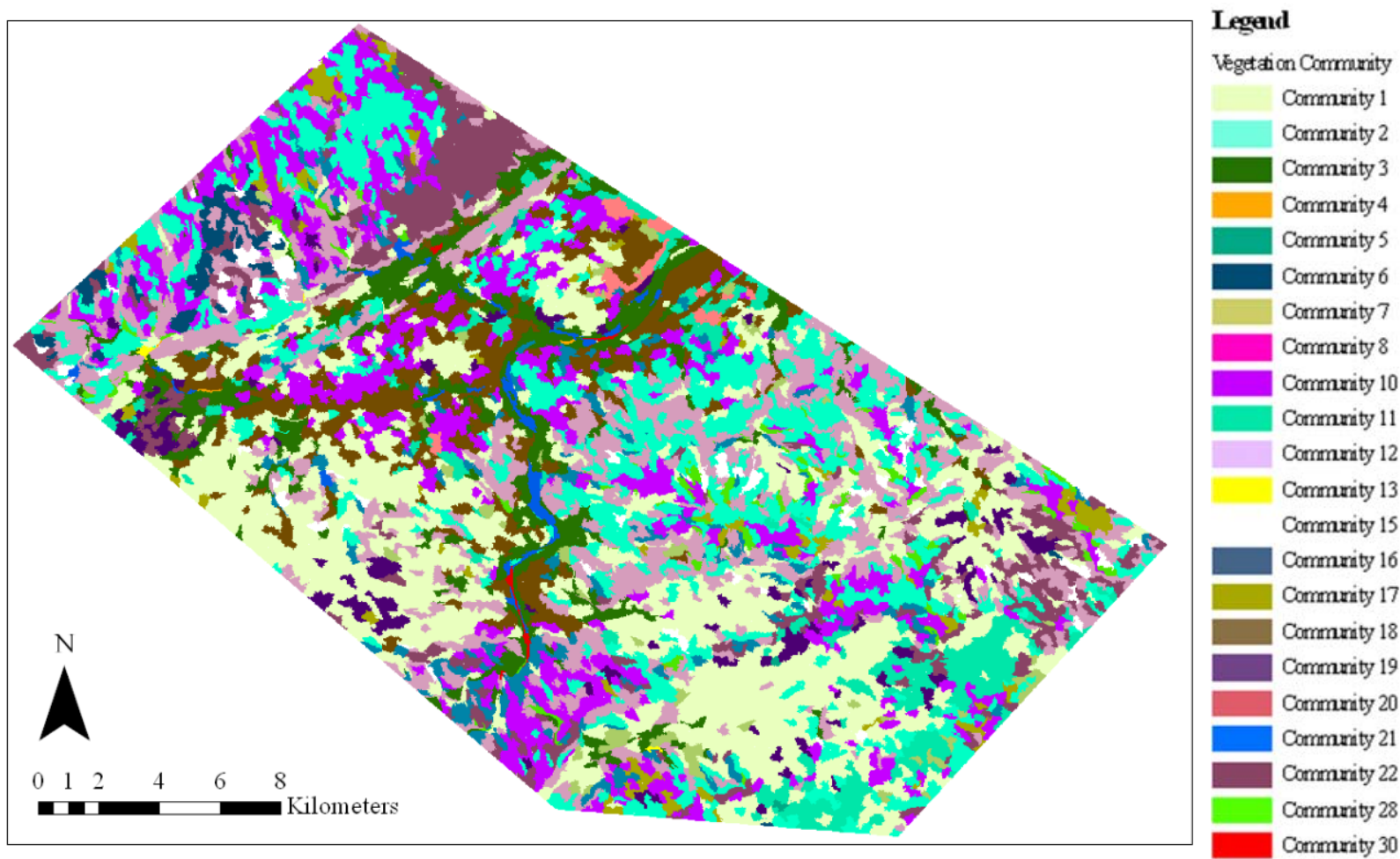

GEOBIA NN integrated: SPOT5 (DEM and slope) at 1:100,000.
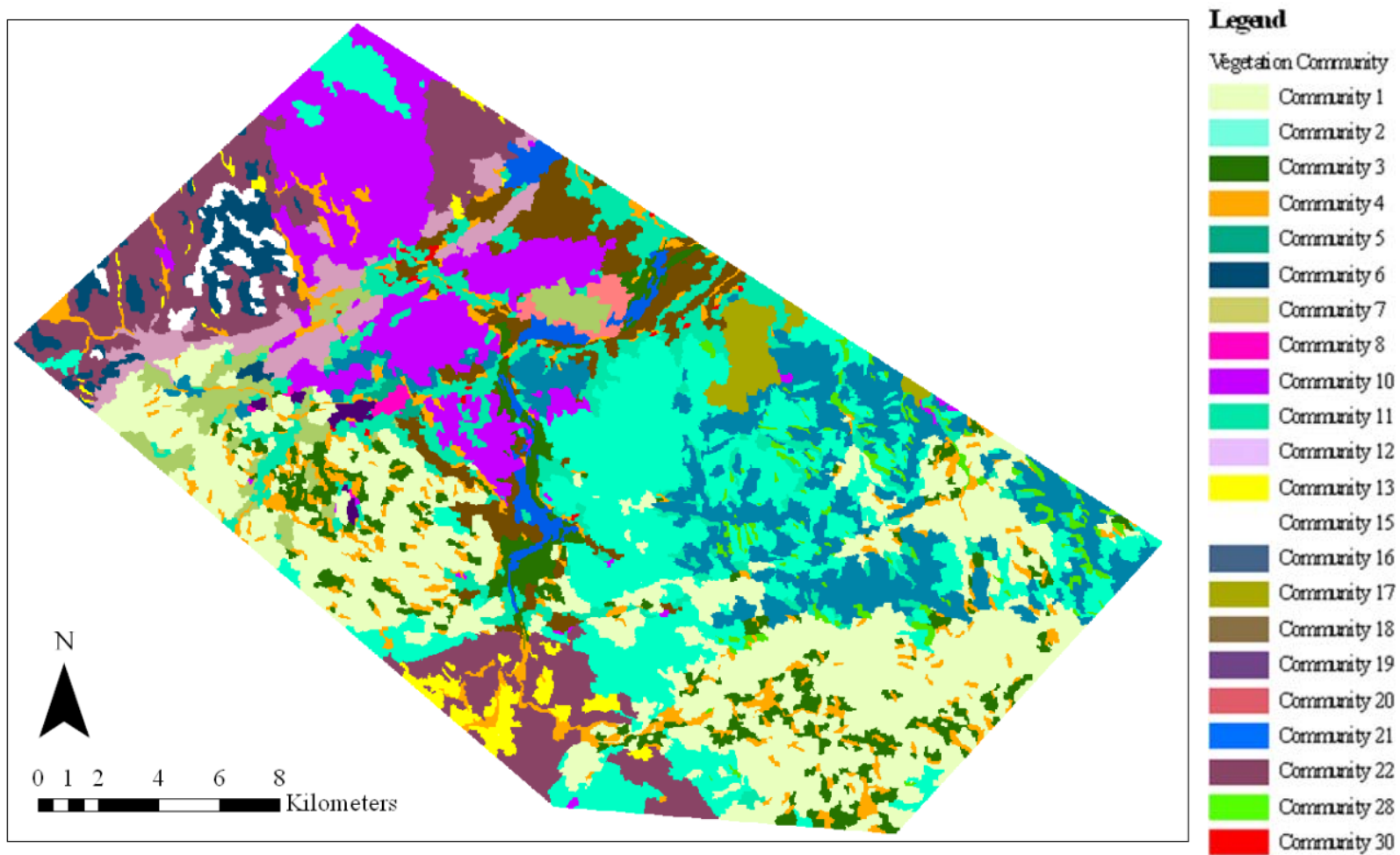

GEOBIA step-wise image-only: Landsat5 TM (contextual information) at 1:25,000. 
Appendix 2. Cont.
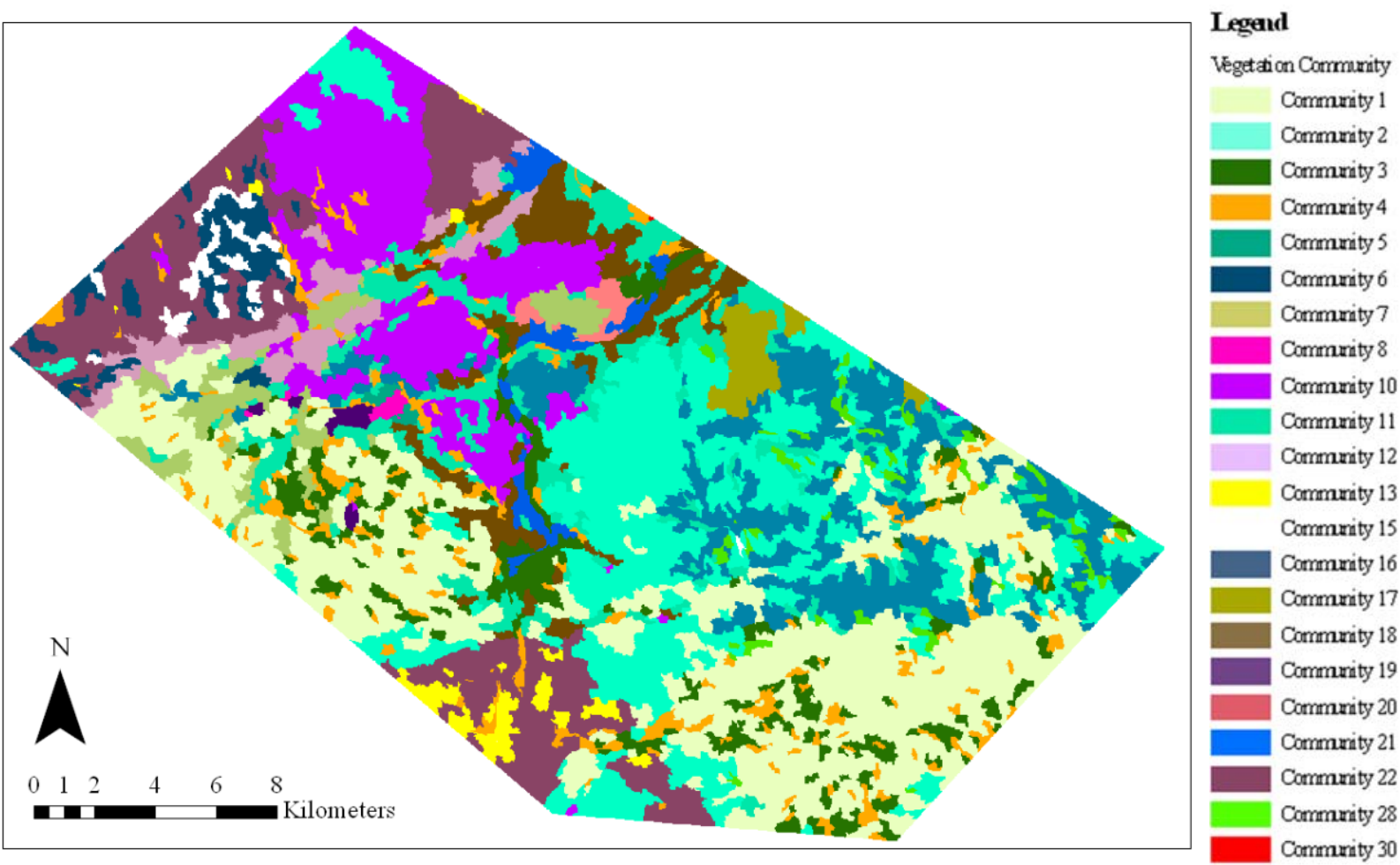

GEOBIA step-wise image-only: Landsat5 TM (contextual information) at 1:100,000.
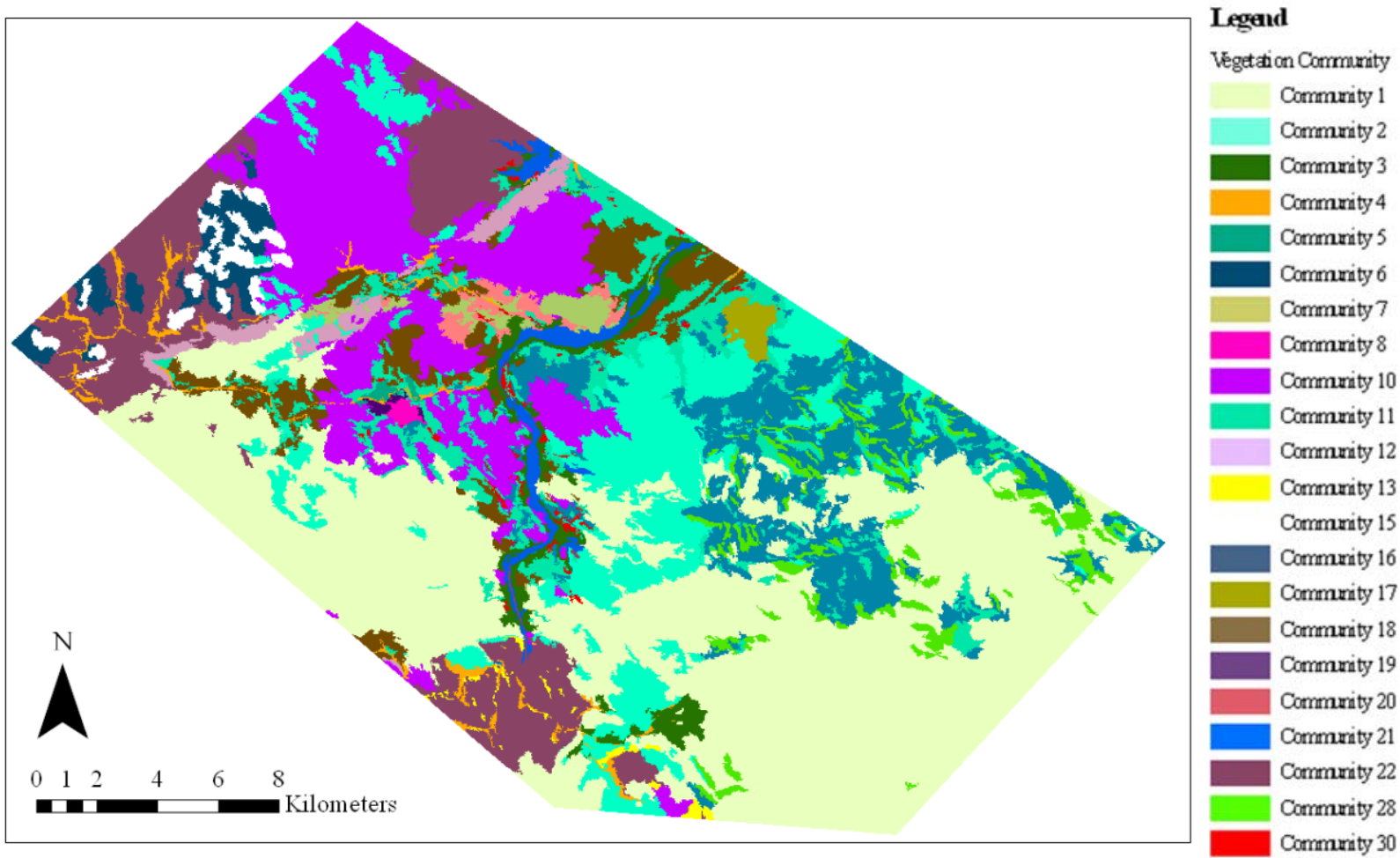

GEOBIA step-wise image-only: SPOT5 (contextual information) at 1:25,000. 
Appendix 2. Cont.
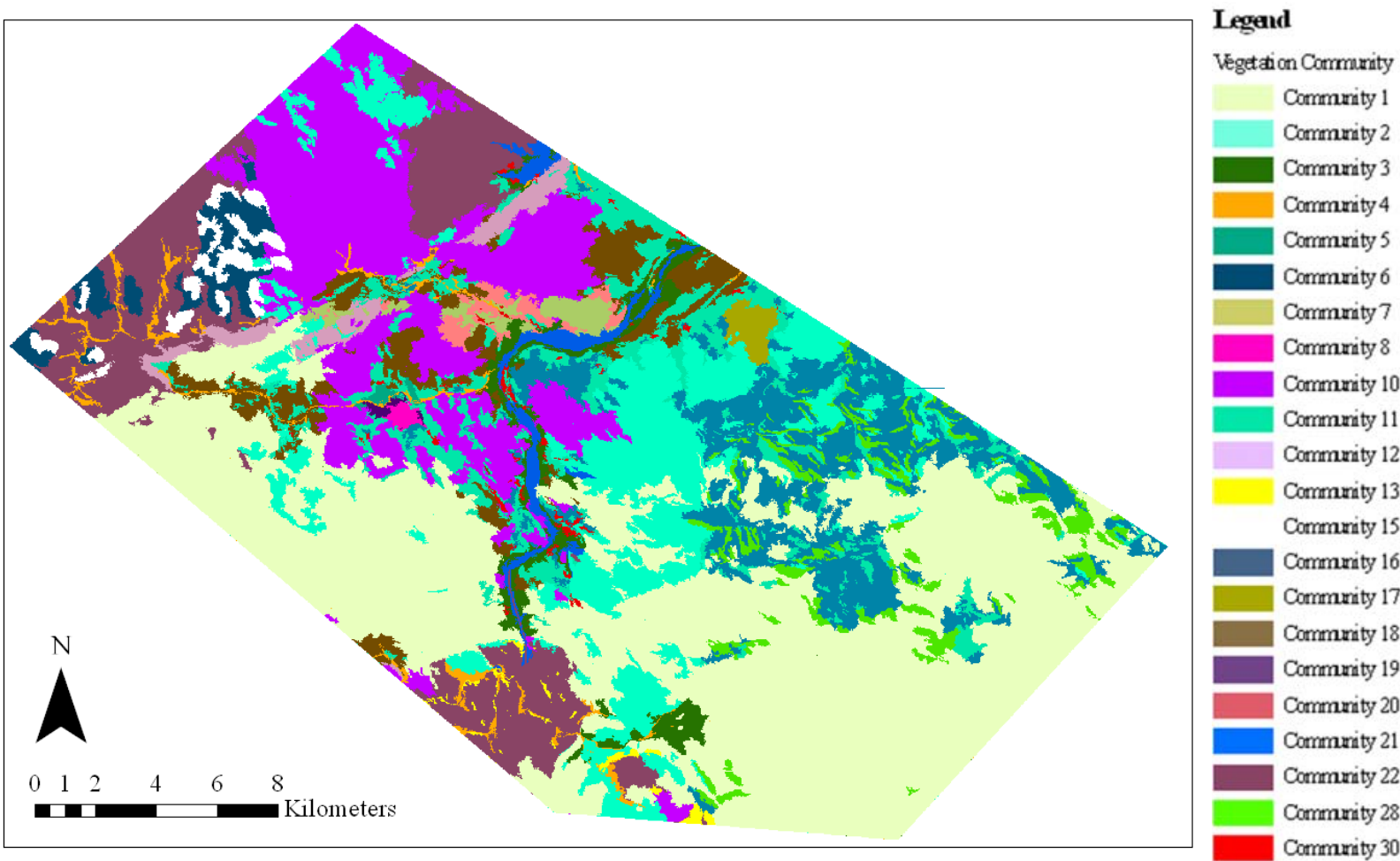

GEOBIA step-wise image-only: SPOT5 (contextual information) at 1:100,000.
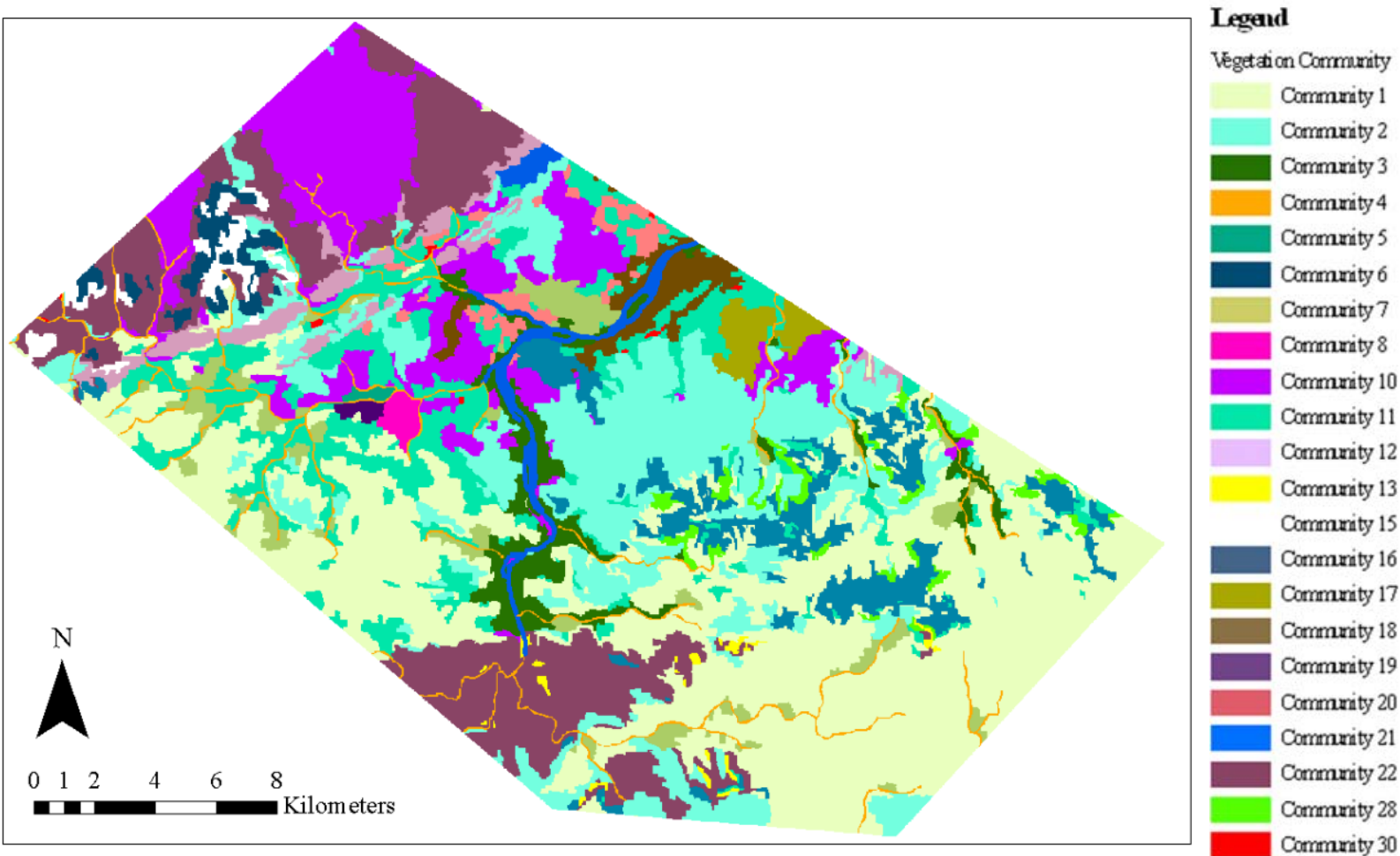

GEOBIA step-wise integrated: Landsat5 TM (DEM, slope and contextual information) at 1:25,000. 
Appendix 2. Cont.
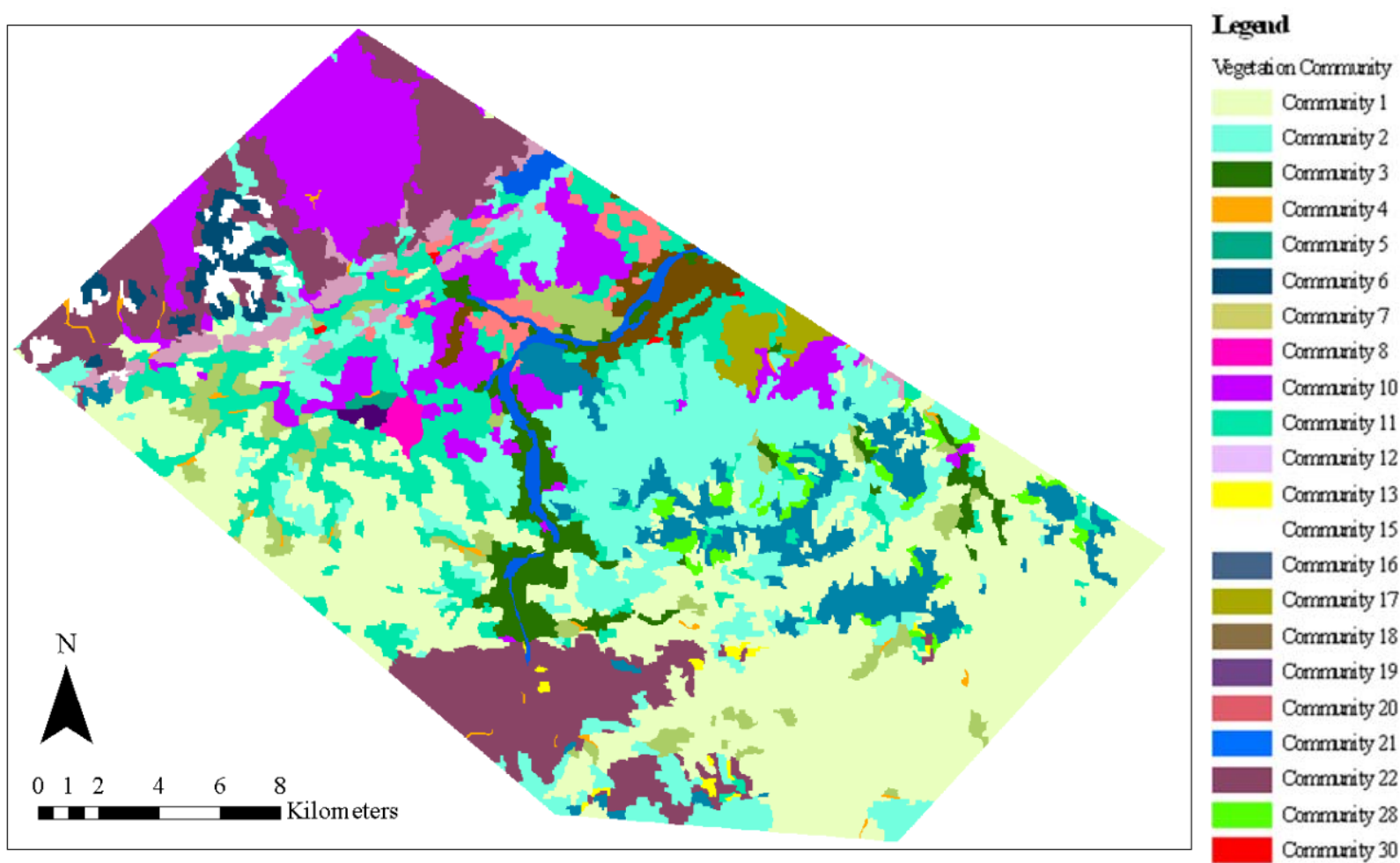

GEOBIA step-wise integrated: Landsat5 TM (DEM, slope and contextual information) at 1:100,000.
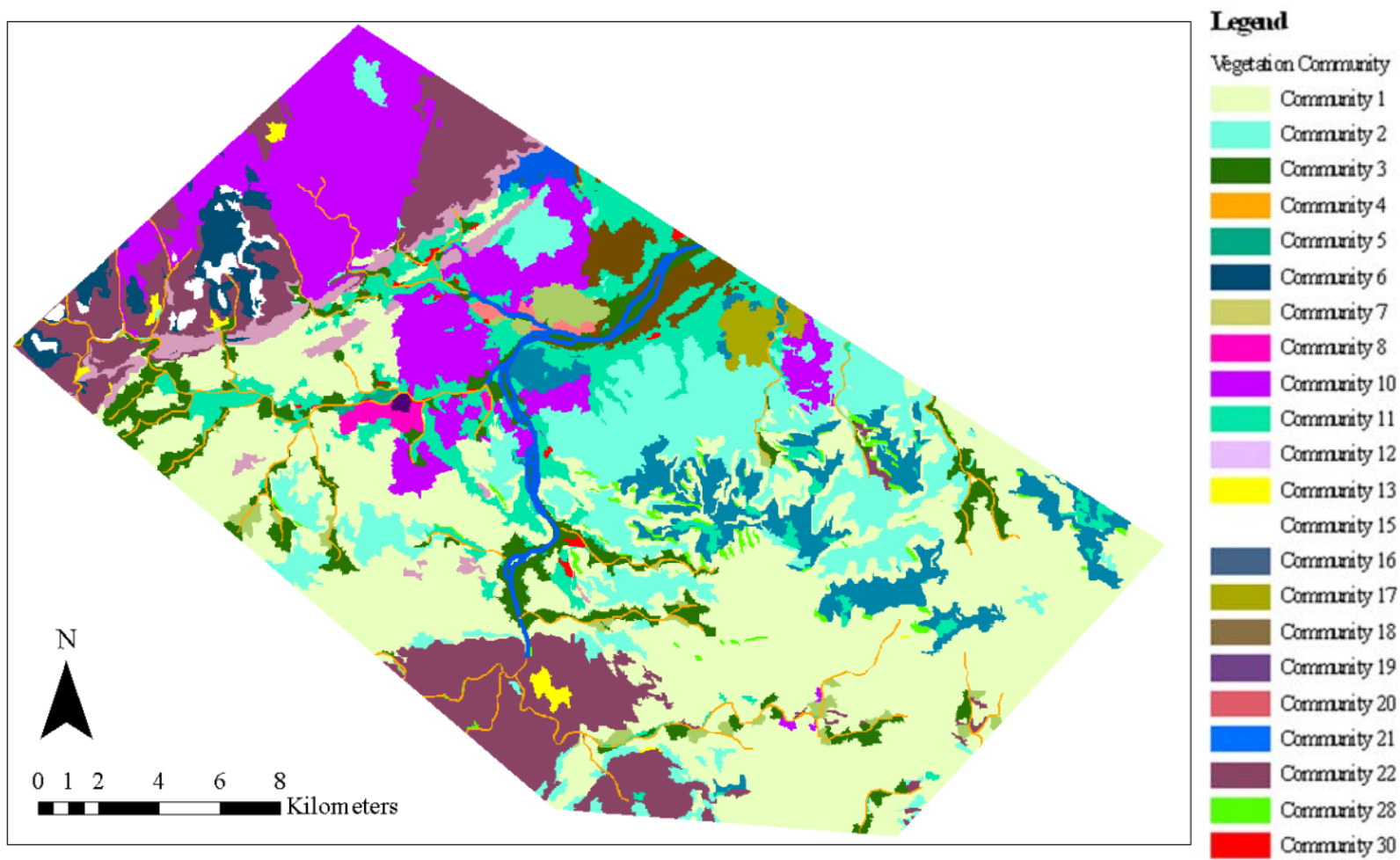

GEOBIA step-wise integrated: SPOT5 (DEM, slope and contextual information) at 1:25,000. 
Appendix 2. Cont.
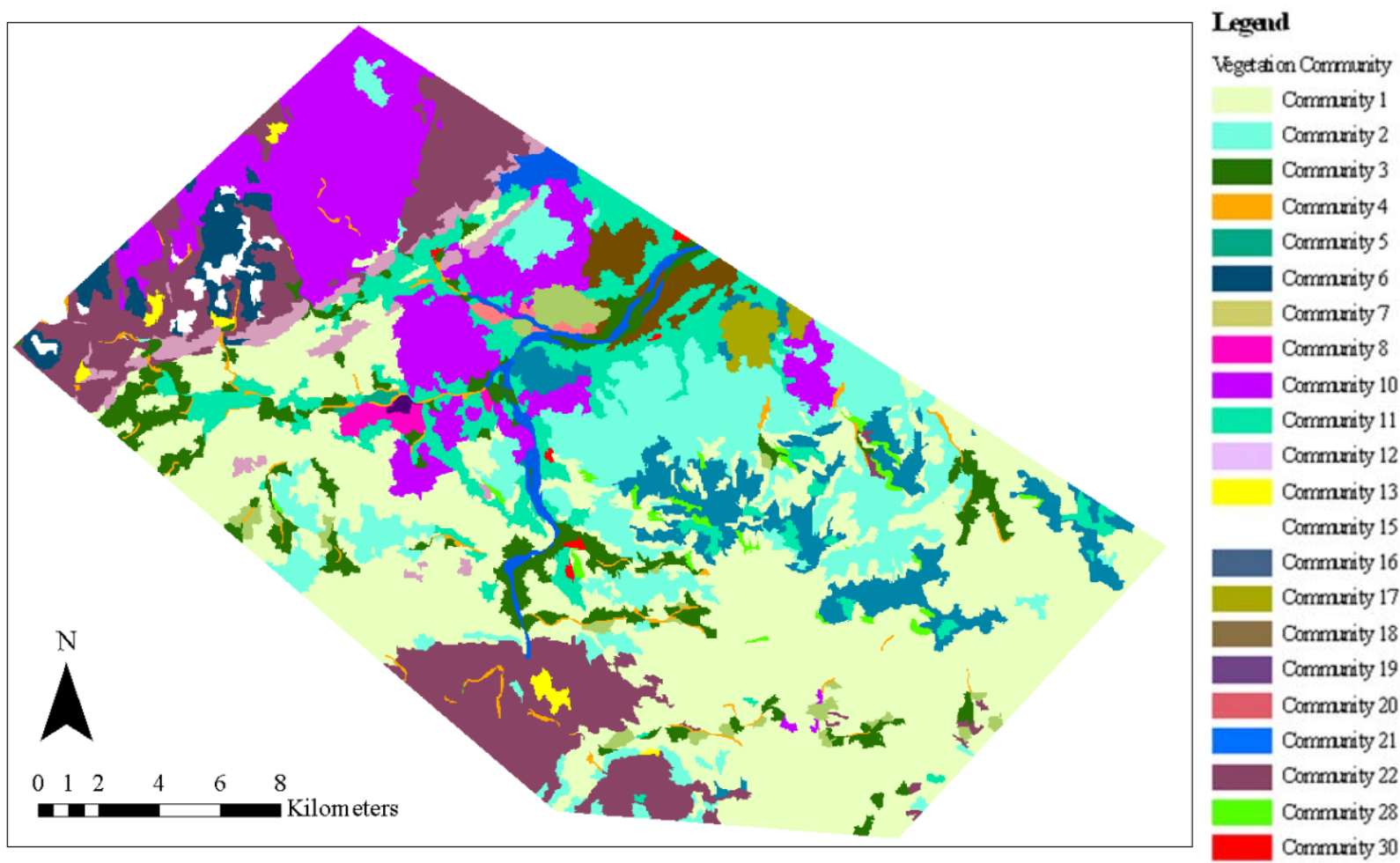

GEOBIA step-wise integrated: SPOT5 (DEM, slope and contextual information) at 1:100,000.

(C) 2013 by the authors; licensee MDPI, Basel, Switzerland. This article is an open access article distributed under the terms and conditions of the Creative Commons Attribution license (http://creativecommons.org/licenses/by/3.0/). 